\title{
Review Article \\ Recent Progress in Stem Cell Modification for Cardiac Regeneration
}

\author{
Heiko Lemcke $\mathbb{D}^{1,2}$ Natalia Voronina, ${ }^{1,2}$ Gustav Steinhoff, ${ }^{1,2}$ and Robert David $\mathbb{D}^{1,2}$ \\ ${ }^{1}$ Department of Cardiac Surgery, Reference and Translation Center for Cardiac Stem Cell Therapy (RTC), University of Rostock, \\ Schillingallee 69, 18057 Rostock, Germany \\ ${ }^{2}$ Department Life, Light and Matter of the Interdisciplinary Faculty, University of Rostock, Albert-Einstein Straße 25, \\ 18059 Rostock, Germany
}

Correspondence should be addressed to Heiko Lemcke; heiko.lemcke@uni-rostock.de and Robert David; robert.david@uni-rostock.de

Received 18 August 2017; Accepted 12 November 2017; Published 16 January 2018

Academic Editor: Jia-Qiang He

Copyright (C) 2018 Heiko Lemcke et al. This is an open access article distributed under the Creative Commons Attribution License, which permits unrestricted use, distribution, and reproduction in any medium, provided the original work is properly cited.

\begin{abstract}
During the past decades, stem cell-based therapy has acquired a promising role in regenerative medicine. The application of novel cell therapeutics for the treatment of cardiovascular diseases could potentially achieve the ambitious aim of effective cardiac regeneration. Despite the highly positive results from preclinical studies, data from phase I/II clinical trials are inconsistent and the improvement of cardiac remodeling and heart performance was found to be quite limited. The major issues which cardiac stem cell therapy is facing include inefficient cell delivery to the site of injury, accompanied by low cell retention and weak effectiveness of remaining stem cells in tissue regeneration. According to preclinical and clinical studies, various stem cells (adult stem cells, embryonic stem cells, and induced pluripotent stem cells) represent the most promising cell types so far. Beside the selection of the appropriate cell type, researchers have developed several strategies to produce "second-generation" stem cell products with improved regenerative capacity. Genetic and nongenetic modifications, chemical and physical preconditioning, and the application of biomaterials were found to significantly enhance the regenerative capacity of transplanted stem cells. In this review, we will give an overview of the recent developments in stem cell engineering with the goal to facilitate stem cell delivery and to promote their cardiac regenerative activity.
\end{abstract}

\section{Cardiovascular Disorders in the Modern World}

Cardiovascular diseases (CVDs) are the major cause of mortality and disability worldwide. In the United States alone, approximately one million myocardial infarctions (MI) occur yearly, and many of these patients develop heart failure, which is currently diagnosed in five million patients [1-3]. Due to the high number of patients and high-cost treatment, CVDs also represent a serious financial burden $[1,4]$. CVDs include various disorders affecting the heart and vessels: coronary heart disease, cerebrovascular disease, peripheral arterial disease, rheumatic heart disease, congenital heart disease, deep vein thrombosis, and pulmonary embolism. Among these, the most frequent cases of tissue ischemia are associated with coronary heart disease, stroke, and peripheral arterial disease, which together account for more than half of all CVDs [4].

Until recently, the heart was suggested to be a terminally differentiated organ incapable of regeneration. However, the most recent findings have proven that at the age of 20 the renewal rate for cardiomyocytes reaches $1 \%$, whereas at 70 it decreases down to $0.4 \%$ per year $[2,5]$. At the same time, even without diagnosed heart disease, cardiac overload or the aging process are associated with significant loss of cardiomyocytes - up to 20 million yearly (to compare, the left ventricle contains 2-4 billion cardiomyocytes). Furthermore, an acute event such as MI causes loss of billions of cells, reaching $25 \%$ of the total heart mass [1]. Since cardiomyocytes are endogenously regenerated in a very limited degree, compensation of this cell loss is achieved by formation of fibrotic scar tissue that does impair heart contractility [2]. 


\section{Cell Therapy for Cardiovascular Regeneration-An Alternative Treatment Approach}

Currently, there are no efficient pharmaceutical or surgical strategies for the prevention of ischemia-mediated damage and for full regeneration of the injured heart tissue [6]. Besides cardiac resynchronization, angioplasty, or ventricular assist devices, several drugs are applied for the management of hypertension or dyslipidemia and for the control of metabolic symptoms [7]. In particular, all current pharmacological treatments applied in heart failure are principally palliative: they are helpful in improving the quality of life but are not able to change the course of disease. In this regard, the only curative option is heart transplantation. Similarly, in MI treatment, even the most successful developments in surgery are restricted to an improvement of blood supply through manipulation of large vessels [8]. At the same time, one of the key mechanisms for inoperable heart conditions is microangiopathy, where the lack of microcirculation is causing ischemia. Thus, current medical developments are not able to significantly change the course of MI too.

To conclude, the current status of therapy for CVDs is insufficient and development of safe and efficient alternative treatments is necessary. Gene or stem cell therapy and their combination are the major promising strategies thereof. In contrast to currently applied treatments, stem cells have the potential to stimulate and support endogenous mechanisms of cardiac repair and thus provide the basis for full regeneration of damaged heart tissue.

2.1. Cell Types Currently Applied. Two main categories of stem cells (SCs) are currently exploited for cardiac regenerative medicine: (1) multipotent adult SCs and (2) pluripotent embryonic SCs (ESCs) and induced pluripotent SCs (iPSCs), where either differentiated derivatives are being explored for transplantation or cells are differentiated in situ after transplantation [9-11]. As potential therapeutics, both these groups carry certain advantages and disadvantages $[10,11]$.

ESCs and iPSCs share significant benefits: pluripotency, efficient expansion in vitro, availability of high cell numbers, and opportunity to create cell banks and off-the-shelf products $[12,13]$. In addition, in case of iPSCs, autologous cells for transplantation are available. At the same time, teratoma formation is possible due to either remainders of pluripotent cells in final differentiated cell fraction or impaired in situ differentiation [12]. Moreover, preparation of the final therapeutic product of these cells-either proliferation or differentiation-requires their prolonged culture. This, in turn, can lead to upregulation of miRNAs commonly found in cancers and increase the possibility of genetic and epigenetic abnormalities [11]. Importantly, the use of allogenic ESCs implies possible severe complications due to immune system reaction. In addition, it has been provoking serious ethical and legal debates for decades [11].

Adult SC group consists of different populations of stem and progenitor cells, isolated from various sources, including bone marrow, circulating blood, or solid resident tissues.
Most commonly applied cell types are the following: bone marrow-derived mononuclear cells, hematopoietic SCs, endothelial progenitor cells, cardiac SCs (CSCs), and mesenchymal stem cells (MSCs). Their clinical development for the treatment of cardiac patients is very advanced: the most of the clinical translation path is undergone by now. A growing number of preclinical and clinical trials have led to serious positive outcomes within the field of adult stem and progenitor cell transplantation for CVD therapy. First, the therapeutic regeneration using cell products has been demonstrated in several clinical trials (RENEW (NCT01508910), PROCHYMAL (NCT00690066), SCIPIO (NCT00474461), FINCELL (NCT00363324), etc.). In addition, attempts to establish an optimal match between cell product and patient's cohort have been made (PERFECT (NCT00950274). Furthermore, bone marrow-derived progenitor cells were found to positively influence patients with the most extensive MIinduced damage including a low baseline of left ventricular ejection fraction (LVEF) (REPAIR-AMI (NCT00279175), FINCELL, and REGENT (NCT00316381)). For other patients, emerging cell types like CSCs may be suitable which will be defined in planned and ongoing clinical trials [14]. Importantly, the possibility of safe allogenic cell therapy without immunosensitization has been proven for MSCs and CSCs (POSEIDON (NCT01087996), PROCHYMAL (NCT00690066), and ALLSTAR (NCT01458405)), which enables the generation of "off-the-shelf" products.

The main risks related to the adult SC transplantation are rare, usually manageable, and similar for all cell products: immunogenicity and possible occurrence of arrhythmias (the latter particularly for MSCs) [2, 10]. Taken together, the clinical use of adult SCs has proven to be safe for transplantation with a certain evidence of clinical efficacy; thus, further phase II and III trials can be initiated. At the same time, although safety and feasibility of these different cell types have been proven in several clinical trials, the beneficial outcome for cardiac performance is usually very limited [2, $15,16]$. In particular, most successful results have been achieved for CSCs ( 10\% functional improvement in phase I clinical trial) $[17,18]$, whereas other commonly applied cell types lead to an average $3-5 \%$ beneficial outcome or no positive effect [19].

A new approach for improving cardiac regeneration has been recently described by Luo et al., who generated functionalized microparticles, mimicking stem cell properties [20]. The authors used biodegradable poly(lactic-co-glycolic acid) to encapsulate the secretome of MSCs, followed by coating of these particles with a MSC-derived membrane. Upon transplantation into infarcted mice hearts, these synthetic cell particles demonstrated a regenerative capacity comparable to MSCs. Likewise, the same group utilized cell membranes derived from CSCs to fabricate "synthetic stem cell" products, which were also found to significantly enhance cardiac remodeling and function in vivo [21]. The clinical application of these "synthetic stem cell" analogs would overcome the hurdles stem cell therapy is facing, including sufficient storage stability of the cell product, stimulation of an immune reaction, and tumourigenicity caused by cell transplantation [22]. 


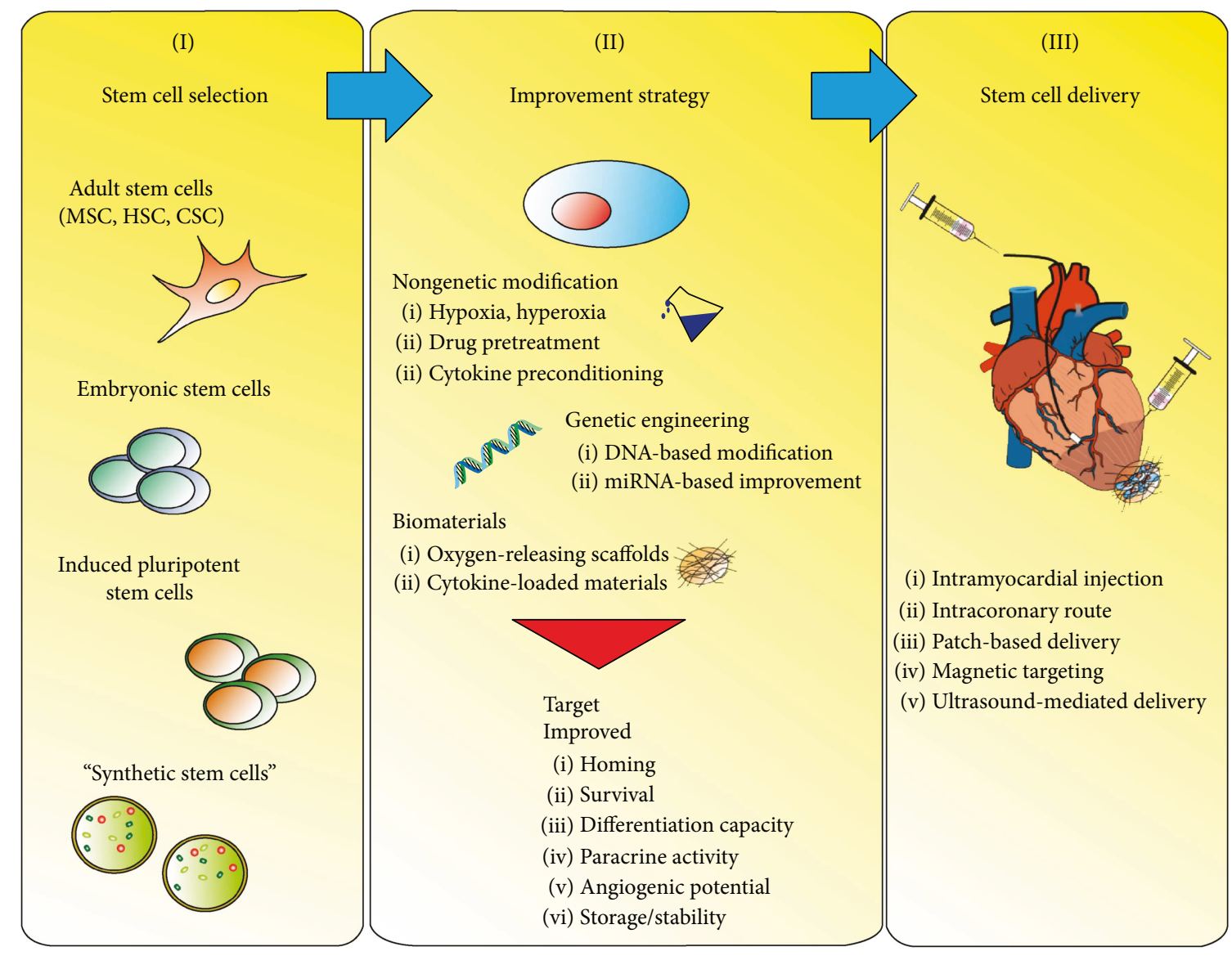

FIgURE 1: Strategies for improving SC-based therapy in CVD treatment. (I) Multipotent adult SCs and pluripotent stem cells, including embryonic SCs and iPSCs, represent the most widely explored cell types for cardiac regeneration. Novel approaches encompass the generation of synthetic particles ("synthetic stem cells"), mimicking stem cell properties. (II) To enhance their therapeutic activity, multiple strategies have been developed and tested in vivo, in some cases reaching clinical trials. While nongenetic modifications are mainly based on the preconditioning with environmental or pharmacological agents, genetic cell engineering utilizes modification on the DNA or posttranscriptional level (miRNA). In addition, the application of cells with supportive biomaterials has proven to greatly increase SC efficiency. The applied strategies positively influence the resistance of SC to the harsh ischemic microenvironment of the damaged heart tissue. Likewise, increased paracrine activity, homing and differentiation capacity, and enhanced proangiogenic activity are common targets for cell improvement. (III) Following successful modification of SC products, optimized administration routes and targeting approaches are developed to ensure proper cell delivery and engraftment.

2.2. Current Difficulties of Cell Therapy. Analysis of existing trials reveals current problems and challenges, which cell therapy for CVDs is facing. First, despite the fact that most clinical trials have been initiated involving adult SCs, analysis of their results is rather challenging. The main reasons are inconsistency of patients' cohort selection and variability in choice of cell population. Other limitations of currently available adult SC therapeutics are the following: available numbers of fractioned bone marrow-derived cells are low, the replicative capacity of adult SCs in situ is limited compared to ESCs and iPSCs, and adult SCs are restricted to a certain lineage. Moreover, the regenerative capacity of cells declines with age and progenitors mobilized in the body may also lack capability with age $[14,23,24]$.

The delivery of sufficient cell numbers to the site of injury also remains a challenging issue. Currently, reported rates of cell retention drop below $5-10 \%$ as soon as several minutes to hours post application, regardless of administration routes
[25-27]. After delivery, the regenerative potential of cells is often compromised by poor engraftment and survival in the ischemic tissue [28, 29]. These factors may explain, at least in part, why the therapeutic benefit of adult SC application is so limited ( 4-5\% functional improvement except primary studies of CSCs) [19]. In addition to the poor delivery of sufficient cell numbers, teratogenic and cancerogenic effects remain one of the biggest concerns for ESC and IPSC application (see Section 2.1).

To conclude, this limited outcome of SC intervention urgently requires improving the therapeutic properties of applied cell types in order to increase their impact on cardiac regeneration (Figure 1).

\section{Strategies to Improve Cell Therapeutics}

3.1. Selection of the Optimal Cell Type. Enrichment of transplanted cells for certain cell populations can significantly 
influence the outcome of therapy. The most illustrative example is selection of cell types from bone marrow based on their properties and surface marker patterns. In particular, uniform isolated cell fractions have demonstrated consistent positive outcomes in several clinical trials (BOOST (NCT00224536), REPAIR-AMI, and FINCELL) versus no functional improvement in many trials involving unselected MNCs (ASTAMI, HEBE, TIME, and Late-TIME). In addition, enrichment of transplanted products for a particular cell type ensures consistency of clinical trials' outcomes and thereby more reliable results. To obtain purified populations of adult SCs from patient's tissue, manual approaches and semiautomatic isolation devices based on magnetic cell sorting have been applied [30].

For resident CSCs, two main categories are currently defined: (1) cardiac progenitors and (2) cardiospheres and cardiosphere-derived cells. To date, eight different CSC subtypes have been identified according to their expression of transcription factors and surface markers, including c-kit and Sca-1 [31].

CSCs expressing the SC factor receptor c-kit are mainly present in the atrium of the ventricular apex at very low density and can be isolated by magnetic bead-based approaches $[32,33]$. These cells are the first CSC population that have been successfully tested in clinical trials and demonstrated a profound increase in cardiac performance [17].

Cardiospheres are generated from the outgrowth of explants obtained from heart biopsies [34, 35]. Notably, due to their bigger size (up to $200 \mu \mathrm{m}$ ), their administration via the intracoronary route (most common in CVDs) bears the risk of microembolization [36]. Yet, the improvement of cardiosphere-manufacturing methods was shown to reduce particle size to $50-100 \mu \mathrm{m}$, making it suitable for a safe delivery via the coronary route in minipigs [37]. However, cardiosphere-derived SCs have been found to represent a better therapeutic product [38]. In the phase I CADUCEUS trial (NCT00893360), autologous cardiosphere-derived SCs, injected into patients suffering from ventricular dysfunction, led to reduced infarction size but lacked functional benefits [39]. Therefore, additional clinical trials need to be initiated to further validate the first promising results and to elucidate the entire regenerative potential of CSCs.

The cell selection in the case of ESCs and iPSCs mainly relates to the successful selection of pure cell populations after differentiation. This serves to ensure that tumorigenic, undifferentiated cells are not transplanted together with the final cell product. Several purification strategies have been established, such as surface marker isolation, manual enrichment, or density gradient centrifugation [40]. Cell enrichment based on the expression of a drug-resistant gene or fluorescent protein is a commonly used method that results in highly purified cell populations of $~ 95 \%$ [40, 41]. In contrast, flow cytometry in combination with antibodies, targeting specific surface markers for certain cell types (kinase insert domain receptor and platelet-derived growth factor receptor $\alpha$ for CSCs and signal-regulatory protein $\alpha$ for adult cardiomyocytes), represents another purification strategy which does not include genetic manipulation [42-45]. In addition, lactate-based enrichment and the application of nanosized probes to detect cell type-specific mRNA were used to generate iPSC-derived cardiomyocyte populations with a purity of more than $90 \%[46,47]$. In terms of clinical compatibility, it is so far preferred to apply purification approaches which preclude genetic modification.

In the only initiated clinical trial for CVD treatment using ESC-derived cardiac progenitors (purity of 99\%), cells were transplanted into an infarct area of a patient with severe heart failure. As a result, at three months follow-up, no complications such as arrhythmias or tumor formation were observed, whereas an improvement of symptoms from New York Heart Association class III to I and an increase in LVEF of $10 \%$ were reported [9]. However, as promising as these results are, much better developed protocols, more data, and long-term proofs of safety are required to bring early progenitors to wide clinical practice [10, 14].

3.2. Improvement of SC Delivery. The outcome of cell therapy for cardiac regeneration strongly depends on the successful delivery of SCs to the site of interest. To date, two major routes of cell administration have been applied in preclinical and clinical studies: (1) systemic (intravenous) injection and (2) local (intramyocardial) transplantation [48]. Although intravenous injection is easy to apply and less invasive than local transplantation routes, injected SCs are widely distributed throughout the whole body and accumulate in the liver, lungs, and spleen $[49,50]$. Moreover, this strategy mainly relies on the homing capacity and cell retention of the SC product [51]. Therefore, direct intramyocardial injection has been the most preferred method in preclinical and clinical trials [31]. Nevertheless, the engraftment of cells after delivery remains a very inefficient process. Studies in large and small animal models, for example, pigs, gave evidence that more than $90 \%$ of cells are washed out within the first hour after transplantation [48, 52-54]. Thus, the use of SCs for cardiac regeneration was accompanied by the development of appropriate equipment to ensure that the cell product reaches the target site. Several advanced delivery strategies were established to ensure minimally invasive and targeted cell delivery to the myocardium, including 3D MyoStar ${ }^{\circledR}$ Injection Catheter combined with $\mathrm{NOGA}^{\circledR}$ electromechanical mapping system, 2D fluoroscopic guidance systems Helix $^{\mathrm{TM}}$ infusion catheter, and the MyoCath $^{\mathrm{TM}}[55,56]$.

3.2.1. Application of Biomaterials. The additional application of biomaterials can enhance the delivery of cells into infarcted myocardium to a significant degree, accompanied by improved cell retention. For instance, the encapsulation of cells using hydrogels allows control over the microenvironment upon cell application. Embedding of CSCs into a hydrogel matrix profoundly increased long-term cell retention and cardiac regeneration three weeks after delivery into infarcted mice hearts [57]. Similarly, incorporation of cardiosphere-derived SCs into a hyaluronan-gelatin hydrogel led to a 3-fold enhancement of cell engraftment and an improvement of left ventricular ejection fraction (LVEF) and neovascularization [58]. Biomaterial-assisted cell delivery is performed either by injection of a SC matrix mixture 
into the heart or by transplantation of a cell-matrix patch. Both of these should be biocompatible and biodegradable and should form nontoxic degradation products [59]. The injection-based approach requires liquid biomaterials that solidify immediately after transplantation [59]. Patch-based strategies, in turn, imply the generation of tissue-like structures in vitro prior to transplantation $[60,61]$.

Importantly, these biomaterials can be additionally modified to contain functional molecules, beneficial for the therapeutic effect of delivered SCs, like insulin-like growth factor 1 (IGF-1), stromal-derived factor 1 (SDF-1), and transforming growth factor $\beta$ (TGF- $\beta$ ) [48, 59, 62, 63]. Moreover, oxygen-releasing scaffolds have been developed to increase the $\mathrm{O}_{2}$ level at the site of transplantation for several hours to days, which further improves survival and proliferation of applied SCs [63-65]. Biomaterials like matrigel, cardiogel, fibrin, or collagen represent biodegradable scaffolds that support adhesion, differentiation, and proliferation of different types of SCs, including ESCs and bone marrow-derived SCs as demonstrated in small and large animals $[48,59]$. For adipose-derived MSCs, it was shown that coinjection with fibrin increased cell retention by $50 \%$ four weeks after transplantation into murine hearts [66]. The supporting effect of biodegradable scaffolds has also been proven in a study with human MSCs that were incorporated into a collagen matrix and applied to rats with MI [67]. The authors showed that human MSC patch application led to improved diastolic properties and significantly enhanced the number of blood vessels in the peri-infarct area by $30 \%$. Likewise, the application of cell-supporting synthetic scaffolds induces proangiogenic effects, as shown in murine hearts [68]. Chung and coworkers used vascular endothelial growth factor- (VEGF) loaded poly-l-lactic acid as a vehicle to transplant CSCs into rat hearts [69]. The density of microvessels was significantly increased by $\sim 25 \%$, and a higher number of cardiomyocytes was determined within the infarcted heart tissue four weeks after cell injection. Another example is polyvinylidene fluoride-based scaffolds, which have been recently produced as vehicles for SC delivery in cardiac regenerative therapy. These scaffolds possess piezoelectric characteristics which may be beneficial especially for the application in cardiovascular tissue. In vitro studies with ESCs and ESC-derived cardiovascular cells already demonstrated the feasibility of polyvinylidene fluoride as a vehicle for SC delivery [70].

3.2.2. Magnetic Cell Targeting. The concept of magnetically targeted delivery implies labeling or loading of SCs with particles responsive to a magnetic field in order to facilitate cell guidance to the area of interest. Using this approach, different research groups have demonstrated successful in vitro and in vivo results. For example, a study by Vandergriff and coworkers demonstrated that magnetic targeting can increase cell retention and engraftment of cardiospherederived SCs to the infarcted rat myocardium $\sim 4$-fold compared to control where no magnet was applied [71]. This enhancement of cell retention was accompanied by augmented angiogenesis, smaller scar size, and improved cardiac performance. Further in vivo studies showed an increased engraftment and functional benefits of magnetically labelled cardiosphere-derived SCs if compared to the nontargeted group [72, 73]. Similar improvement of cell retention was observed by Shen et al. $24 \mathrm{hrs}$ after transplantation of MSCs in a rat MI model. However, a long-term analysis of these animals (three weeks) showed less pronounced differences between magnetically targeted and nontargeted cells [74]. Interestingly, the data also suggested that too high magnetic intensity can cause microembolization and hamper the positive effect on cardiac performance [74]. Another promising study has been published by Cheng and coworkers in 2014 [75]. Superparamagnetic iron nanoparticles were simultaneously conjugated with two antibodies targeting $\mathrm{CD} 45^{+}$ therapeutic endogenous SCs and injured cardiomyocytes [75]. After intravenous injection of these particles into the injured myocardium of rats and local application of a magnetic field, targeting of $\mathrm{CD} 45^{+}$cells to the infarcted region was enhanced 10-fold, as well as their therapeutic activity [75]. Importantly, as various studies in small and large animals have demonstrated, magnetic nanoparticles are also applicable to track cells via MR imaging [76-79].

To date, magnetic particles have been used in several in vitro and preclinical studies [80-84]. However, some safety concerns need to be addressed before wide clinical translation. In particular, increased iron concentrations can increase the intracellular level of free radicals (in a dose-dependent manner) [84]. Moreover, the application of strong magnetic fields can have enhancing or inhibiting effects on biological systems or lead to the formation of toxic aggregates from intracellularly located magnetic particles [84-86]. In addition, certain limitations should be taken into account when using magnetic nanoparticles for imaging of transplanted SCs: it is difficult to distinguish between magnetized viable and dead cells; and long-term MRI-based follow-up of injected cells is compromised due to the leakage of iron particles or their uptake by macrophages $[23,77,87]$. At the same time, the use of MR reporter genes might help to overcome this problem. Overexpression of the transferrin receptor or ferritin are commonly used to augment the intracellular iron concentration and profoundly enhance contrast in MRI tracking $[88,89]$.

3.2.3. Ultrasound-Mediated Delivery of SCs. The application of microbubbles to tag cells followed by ultrasoundmediated cell targeting is a novel technique that can significantly promote cell retention and engraftment at the site of injury. In this concept, gas-filled microbubbles are attached to the SCs, which thereby become highly susceptible to acoustic radiation forces. Thus, SCs can be placed and arrested at the injured area using ultrasound catheter intracoronary injection $[90,91]$. In particular, in a rabbit model, the application of microbubble-tagged MSCs and ultrasound led to a 150-fold enrichment of cells at the endoluminal surface [90]. Such enhanced efficiency of cell delivery via microbubble/ultrasound system was confirmed in a large animal model [92]. In this study, the increased MSC engraftment was accompanied by a slight but significant improvement of cardiac functions and cardiac remodeling after MI in dogs [92]. Moreover, Woudstra and colleagues designed microbubbles coated with antibodies, targeting both the 
SC-specific marker CD90 and an adhesion molecule expressed on endothelial cells within the infarcted area. This experimental setup allowed specific delivery to the damaged myocardium in a rat MI model, while almost no cells were found in the noninfarcted area [93].

3.3. Nongenetic Modification to Improve SC Efficiency. Once SCs are delivered to the infarcted area, long-term survival and engraftment are prerequisites for sufficiently exerting their therapeutic activity and to establish successful clinical treatments. Numerous ex vivo manipulation strategies have been employed to increase survival, homing, and engraftment of injected SCs [48, 63, 94]. Nongenetic approaches and genetic cell engineering are applied to generate a "second generation" of SC therapeutics, which should come close to the ultimate goal of regenerative medicine to renew defected cardiac tissue with new functional cells.

3.3.1. Hypoxic Pretreatment of SCs. The harsh microenvironment within damaged host cardiac tissue is one of the major obstacles for transplanted SCs. Low oxygen levels, deprived nutrient supply, oxidative stress, and inflammatory mediators impede successful engraftment and lead to cell death early after transplantation [95]. Hypoxic priming of SC prior to transplantation was found to stimulate endogenous cell defense mechanisms, thereby increasing cell survival and improving the beneficial effects of SC therapy [96-98]. In numerous preclinical studies, duration of hypoxia varied from hours to days, while the level of hypoxia commonly ranged between $0.5 \%$ and $3 \%[96,99]$. In the study of Hosoyama et al., transplantation of hypoxia-preconditioned cardiosphere-derived SC sheets into infarcted mice hearts improved left ventricular function and decreased infarction size, compared to SCs that were cultured under normoxic conditions [99]. Similar results were previously observed by other researchers that have applied hypoxia-preconditioned SCs to murine MI-treated hearts $[96,100]$. In a large animal model, application of MSCs subjected to hypoxia for one day resulted in a significant increase of ventricular function and capillary density in infarcted pig hearts [101]. Apart from the positive impact on cardiac function and tissue regeneration, hypoxia was also found to improve cell engraftment, leading to $30 \%$ increase in the amount of SCs retained in the ischemic area [101].

The underlying mechanisms mediating the positive effects of hypoxic preconditioning are diverse. In terms of cell engraftment, it was shown that hypoxia increases the expression of CXC chemokine receptor 4 (CXCR4), a receptor involved in cell homing [102-104]. As a result, SC migration to the infarcted tissue was profoundly augmented in vivo, which was also demonstrated in numerous in vitro studies [103, 105-108]. Moreover, the upregulation of prosurvival and antiapoptotic factors facilitates cell survival after injection $[96,109,110]$. This higher cell viability is also supported by a lower level of damaging reactive oxygen species that was observed when cells were subjected to decreased oxygen levels [100]. In addition, hypoxia activates many signaling pathways, such as AKT or MAPK, leading to increased secretion of paracrine factors that contribute to cardiac regeneration [111-113].

3.3.2. Preconditioning with Pharmacological Agents. Pretreatment of cells with pharmacological agents is another simple and cost-effective approach to improve their therapeutic activity. Drug-mediated preconditioning promotes the release of certain paracrine factors, including SDF-1, hepatocyte growth factor (HGF), or IGF which, in turn, are advantageous for the regeneration after cardiac injury $[110,114$, 115]. Furthermore, certain chemical molecules can possess antiapoptotic properties increasing therefore the survival of applied SCs. In particular, pharmacological activation of Rap1, a GTP-binding protein, was found to improve survival and adhesion of transplanted MSCs and restore function of MI-treated rat hearts [116]. Similarly, selective activation of the cannabinoid receptor type two in injected adiposederived SCs positively influenced the remodeling process and improved cardiac functions in mice, probably by enhancing paracrine signaling of SCs and resistance to oxidative damage [117].

Paracrine signaling was proven to be one of the major mechanisms mediating the regenerative capacity of SCs. At the same time, the direct conversion into cardiomyocytes also contributes to the benefits provided by SC therapy [118-120], and pharmacological treatment was shown to facilitate the myogenic differentiation. For example, the DNA demethylating agent 5-azacytidine was extensively described to enhance the differentiation of SCs into cardiaclike cells in vitro [121-124]. Moreover, preincubation with 5-azacytidine significantly promoted the cardiogenic differentiation capacity of MSCs when transplanted into pig hearts, although a positive effect on cardiac performance was not detected [125]. The latter is in line with a report by Mykhaylichenko et al., where 5-azacytidine-modified SCs did not profoundly improve cardiac function and morphological parameters, for example, size of infarction area [126]. Thus, novel pharmacological strategies need to be established to promote the capacity of SCs for cardiac lineage specification. However, even if applied SCs demonstrate cardiac-specific markers after transplantation, successful integration into the host myocardium is required in order to significantly enhance contractility.

Notably, application of chemical compounds also plays an emerging role in SC-based generation of cardiac cells by stimulation or inhibition of cellular signaling pathways such as Wnt or bone morphogenetic protein (BMP) [127-129]. These small molecule-mediated programming/reprogramming strategies help to improve the quality of in vitro-produced cardiac cells suitable for the transplantation into ischemic hearts to replace damaged tissue $[130,131]$.

3.3.3. Application of Growth Factors and Cytokines. In addition to pharmacological agents, growth factors and cytokines are powerful molecules to influence SC activity. Several molecules have been shown to determine cell fate towards the cardiogenic lineage. For instance, fibroblast growth factors (FGF) or BMP4 are promising compounds that promote the differentiation of SCs into cardiac-like 
cells or cardiomyocytes and thus can be applied to prime cells before injection [132]. In particular, in a phase II C-CURE clinical trial (NCT00810238), lineage-guided MSCs were found to be safe and beneficial in chronic heart failure [133]. In this case, MSCs were exposed ex vivo to various growth factors and cytokines (TGF- $\beta$, BMP4, FGF, etc.) mimicking natural cardiogenic conversion prior to transplantation. As a result, a significantly improved LVEF and six-minute walk distance were demonstrated, which highlight the potential of lineage-guided SCs for the treatment of ischemic heart failure [133].

Since growth factors and cytokines are key players in cellular physiology, they have been used to manipulate different signaling pathways in order to modify SC properties apart from cell fate commitment. For example, incubation with SDF-1 before injection enhanced the capacity of endothelial progenitor cells to promote angiogenesis, indicated by increased network formation in vitro [134]. As shown by Pasha et al., the transplantation of SDF-1 primed bone marrow-derived MSCs in rats suffering from MI significantly improved cardiac performance and cardiac remodeling as indicated by reduced infarction size and fibrosis [135]. Additional administration of a CXCR4 agonist abolished the observed positive effect of MSCs on myocardial repair. Moreover, an enhancement of SC efficiency in rats was also observed following TGF- $\alpha$ treatment, leading to a greater postischemic myocardial functional recovery compared to untreated cells [136]. The authors suggested that the improved efficiency of applied SCs is based on a reduced myocardial production of proinflammatory cytokines and on the TGF-mediated upregulation of VEGF in preconditioned MSCs [136].

3.4. Genetic Modification to Improve SC Efficiency. In contrast to nongenetic approaches, genetic modification is another concept to boost the potency of SC products. In general, four main strategies of genetic modification can be applied: protein overexpression by DNA delivery, gene silencing (e.g., by RNAi), gene editing (TALENs, CRISPR/ Cas9), and miRNA-based modifications [137, 138].

3.4.1. DNA-Based Cell Modification. Since the paracrine activity of SCs is of great importance for their regenerative capacity [2], the overexpression of therapeutic factors can be induced, which are normally released by the cell to support cardiac regeneration upon ischemia (VEGF, HGF, IGF, SDF-1, FGF, etc.) $[95,139]$. For instance, viral transduction of adipose-derived MSCs with an IGF-1 construct enhanced the release of IGF, VEGF, and HGF and improved the ejection fraction 6 weeks after cell injection into rats with MI [140]. However, despite the fact that IGF-1 was shown to have an antiapoptotic effect on cells transplanted in the ischemic environment, no transplanted cells were detected at this time point [141]. This indicates that long-term cell survival in this experimental setup was not improved by IGF-1 overexpression. In a similar study, Gómez-Mauricio and coworkers induced overexpression of both IGF-1 and HGF in adipose-derived pig SCs followed by their injection in pig MI model [142]. Animals treated with these modified cells showed reduced inflammation and improved angiogenesis, although no beneficial effect on cardiac function parameters were detected.

To increase SC attachment to the extracellular matrix of the host tissue, Li et al. selected integrin $\beta 1$ as a target protein for overexpression studies [143]. As a result, echocardiography of MI-treated mouse hearts indicated a $\sim 25 \%$ improvement of cardiac performance as well as SC survival one week after transplantation. This is in accordance with previous observations of Mao et al. showing that manipulating integrin signaling pathway is a suitable tool for promoting the therapeutic outcome of MSC transplantation in pigs, including lower degree of fibrosis, increased myocardial perfusion, and microvessel density [144]. Other promising targets, which also have demonstrated a positive effect on SC viability, are the apoptosis-regulating protein BCL-2 and the channel-forming connexin $43[95,145]$. Moreover, overexpression of several proteins, including NKX2.5, TNNIK, hypoxia-inducible factor-1, CXCR4, and AKT1, has been proven to enhance homing, survival, and differentiation of SC $[95,146,147]$.

Taken together, the data shows that the overexpression of proteins in SCs can significantly improve their efficiency and support cardiac regeneration. At the same time, the most commonly applied method for DNA delivery to cells is viral transduction-mainly due to its high efficiency $[148,149]$. Yet, in terms of clinical translation, the use of viruses is suboptimal due to safety issues, including mutagenesis, tumorigenesis, and potential immune reaction of the host. This could be solved via nonintegrating (incl. nonviral) delivery systems. Likewise, the use of DNA itself as a therapeutic molecule carries similar risks as it can be randomly inserted, possibly leading to malignant transformation. One strategy to reduce undesired activation of oncogenic genes is the application of the novel CRISPR/Cas9 gene editing technology that allows precise insertion of therapeutic genes into the SC genome without causing a dysfunction of neighboring genes $[137,138]$.

3.4.2. miRNA-Based Cell Modification. miRNAs are small 20-25-nucleotide-long noncoding RNAs that regulate gene expression on mRNA level. Since their discovery in 1993, miRNAs have been identified to play a crucial role in various cellular processes, including development, cell fate commitment, proliferation, and cell signaling [150-153]. In cardiac regeneration, the ability of miRNAs to promote SC survival by increasing the resistance to high oxidative stress was demonstrated for let-7b [154]. By targeting caspase-3, let$7 \mathrm{~b}$ regulated apoptosis and autophagy in MSCs. Three days after injection, the number of cells that resided in the infarcted heart was twice higher compared to unmodified cells. Moreover, cardiac function was restored [154]. Likewise, miR-133, miR-126, and miR-301 engineered SCs exhibit an improved survival and engraftment when transplanted into MI-treated hearts $[94,155,156]$.

In addition to prosurvival and homing activity, ex vivo modification of SCs with miRNA was also applied to modulate their paracrine activity. For example, following transfection with miR-146 of MSCs, the expression and paracrine 
release of VEGF were enhanced by $300 \%$. These, in turn, promoted the angiogenic effect in vitro and in vivo, leading to reduced fibrosis and improved ejection fraction in murine hearts [157]. Likewise, miR-126 and miR-377 were identified as promising candidates to modulate the release of VEGF in cells prior to transplantation $[158,159]$. In contrast to the use of described miRNA mimics, enhancement of the angiogenic capacity of hiPSCs was also achieved when miR-495 was inhibited. As a result, an increased neovascularization in the infarcted heart was observed as well as integration of SCs to coronary vessels [160].

As mentioned earlier, transdifferentiation of transplanted cells contributes to the regenerative capacity of SCs [118-120]. In this case, the modulation of miRNA expression is beneficial to trigger a cardiac cell fate. This was investigated in a large number of in vitro studies. In particular, combination of 5-aza treatment and miR-1-2 overexpression provoked the activation of cardiac-specific genes in MSCs via the Wnt-signalling pathway [161, 162]. Similarly, cardiac lineage specification of ESCs was enhanced upon miR-1 overexpression [163]. In addition, the let-7 family was found to stimulate the maturation of ESC-derived cardiomyocytes [164].

Compared to DNA-based approaches, miRNA application offers the possibility to induce transient effects which improve the therapeutic properties of SCs. Since no alterations of the genome are required, this epigenetic modification is likely favorable for future clinical translation. However, as miRNAs could have multiple targets, off-target effects need to be addressed when applied as SC modifiers. In addition, expression of the same gene can be regulated by several miRNAs and their possible compensation should be accounted.

A selection of improvement strategies applied in clinical trials and in vivo studies is illustrated in Table 1.

3.5. Tissue Preconditioning. Injured tissue preconditioning is a complementary method to the preconditioning strategy of transplanted stem cells. The main reason of this approach is to produce a more favourable microenvironment for the applied stem cells, leading to improved cell engraftment [176]. It was reported that ischemic postconditioning can increase the beneficial effects of MSC transplantation by improving engraftment and cell survival [177, 178]. More recently, it was discovered that these positive effects of MSC injection were mainly attributed to the hospitable environment [179]. Likewise, pharmacological pretreatment with statins was found to promote the survival and the therapeutic effects of bone marrow and adipose-derived SCs on damaged myocardium [180, 181]. Additionally, physical cues were utilized to make the transplant site more susceptible to donor cells. The application of low-energy shock waves was shown to increase the expression of chemoattractant factors in a rat model of chronic limb ischemia, resulting in an enhanced recruitment of transplanted endothelial progenitors [182]. As a recent report indicated on the clinical trial CELLWAVE, pretreatment with shock waves increased cell homing of injected bone marrow-derived mononuclear cells to the target area and promoted the outcome of cell therapy [170].

\section{Strategies to Improve MSCs}

Among the cell types used as cell therapeutics in cardiac regeneration, MSCs are one of the most attractive for several reasons. First, MSCs can be easily isolated from different tissues, including bone marrow, peripheral blood, umbilical cord, and adipose tissue [148]. Next, they can be amplified in vitro and subjected to genetic and nongenetic cell engineering modifications, although possible disadvantages of ex vivo culturing should be accounted (see Section 2.1) [95]. The regenerative potential of MSCs has been proven by now, whereas the mechanistic basis of it is still under investigation. To date, their capacity for multilineage differentiation has been demonstrated, as well as the ability to control SC niches (in HCS and bone marrow) and the secretion of proangiogenic paracrine factors (VEGF, basic FGF, and PDGF) [183]. In addition, an immunomodulatory and immunosuppressive activity of MSCs has been well described both in vitro and in vivo $[148,184]$. At the same time, the reports on MSC transdifferentiation to cardiomyocytes are controversial.

Due to all beneficial properties characterizing MSCs, a lot of progress has been made to bring them from bench to bedside. Even though safety and feasibility of allogenic and autologous MSC transplantation has been shown in several clinical trials, the conclusions regarding their efficiency and therapeutic outcome differ $[15,148,185]$ (Table 2). Therefore, it is of particular importance to develop clinically relevant improvement strategies which can be utilized to modify MSCs.

Among the previously mentioned engineering approaches applied to MSCs (Sections 3.1-3.4), genetic modification is likely the most promising one, mainly because of its multimodality and ability to cover several challenges for SC therapy, simultaneously [186]. For example, the introduction of reporter genes allows isolation of highly purified cell populations by flow cytometry or the tracking of transplanted cells (e.g., as a result of expression of fluorescent or luminescent proteins) $[187,188]$. Moreover, forced expression of certain factors with high cardiogenic potential can be achieved in transplanted cells [189]. In addition, introduction of factors, which are responsible for such innate cell properties as mobilization, adhesion, migration, or integration, can enhance MSC retention and activity in the desired area $[143,190,191]$. A similar outcome can be achieved by enhancing intrinsic cell properties, that is, their survival in an ischemic environment or their paracrine potential $[145,191,192]$. Furthermore, a broad spectrum of therapeutic agents can be incorporated in order to specifically complement and promote regenerative properties of delivered cells $[159,193]$.

4.1. Improvement of MSC Resistance: Induction of Prosurvival Proteins. A large amount of in vitro data and preclinical studies indicated that MSCs overexpressing therapeutic molecules showed higher potency in the treatment of CVDs. For example, Akt-modified bone marrow-derived MSCs exhibited an increased survival in the myocardium of murine hearts up to two weeks after transplantation $[95,110]$. 
TABLE 1: Selection of clinical trials applying stem cell therapeutics for CVD treatment and examples of developed improvement strategies.

\begin{tabular}{|c|c|c|c|c|}
\hline Cell type & $\begin{array}{l}\text { Clinical trials in } \\
\text { CVD treatment }\end{array}$ & Main effect of cell therapy & $\begin{array}{l}\text { Improvement strategy } \\
\text { (indicated whether tested } \\
\text { in clinical trials or in vivo) }\end{array}$ & $\begin{array}{l}\text { Main outcome of } \\
\text { improvement strategy }\end{array}$ \\
\hline \multirow{3}{*}{ HSCs and EPCs } & PERFECT [165] & $\begin{array}{l}\text { No improvement } \\
\text { (slight improvement } \\
\text { in responder group) }\end{array}$ & $\begin{array}{l}\text { In vivo: delivery by polymer } \\
\text { micro-bundle scaffold [166] }\end{array}$ & $\begin{array}{l}\text { Enhanced cell survival } \\
\text { and retention }\end{array}$ \\
\hline & REGENT [167] & Slight improvement & $\begin{array}{l}\text { In vivo: pretreatment with } \\
\text { deacetylase inhibitor [168] }\end{array}$ & $\begin{array}{l}\text { Enhanced CXCR4 and } \\
\text { VEGF level, increased } \\
\text { vessel formation in } \\
\text { ischemic muscle }\end{array}$ \\
\hline & ACT34-CMI [169] & Improved exercise tolerance & & \\
\hline \multirow{5}{*}{ MSCs } & & & $\begin{array}{l}\text { Clinical trial (CELLWAVE): } \\
\text { cardiac shock wave } \\
\text { pretreatment }[170]\end{array}$ & $\begin{array}{l}\text { Improved retention, } \\
\text { increased LVEF and } \\
\text { cardiac remodeling }\end{array}$ \\
\hline & C-Cure [133] & $\begin{array}{l}\text { Improvement of LVEF } \\
\text { and } 6 \text { min walk distance }\end{array}$ & $\begin{array}{l}\text { Clinical trial: } \\
\text { (C-CURE; CHART I/II) } \\
\text { cell preconditioning with } \\
\text { procardiogenic cytokines }\end{array}$ & Increased LVEF \\
\hline & Chart I/II [171] & $\begin{array}{l}\text { No improvement, } \\
\text { ongoing (CHART II) }\end{array}$ & $\begin{array}{l}\text { In vivo: ultrasound-mediated } \\
\text { delivery [92] }\end{array}$ & $\begin{array}{l}\text { Increased engraftment, } \\
\text { improved cardiac } \\
\text { remodeling and function }\end{array}$ \\
\hline & & & $\begin{array}{l}\text { In vivo: pharmacological } \\
\text { activation of Rap1 [116] }\end{array}$ & $\begin{array}{l}\text { Improved homing } \\
\text { capacity and cardiogenic } \\
\text { differentiation, increased } \\
\text { cardiac performance }\end{array}$ \\
\hline & & & $\begin{array}{l}\text { In vivo: miR-146-based } \\
\text { modification [157] }\end{array}$ & $\begin{array}{l}\text { Augmented VEGF } \\
\text { secretion, improved } \\
\text { cardiac remodeling } \\
\text { and angiogenesis, } \\
\text { improved heart function }\end{array}$ \\
\hline \multirow{3}{*}{ CSCs } & SCIPIO [17] & $\begin{array}{l}\text { Improvement of LVEF, } \\
\text { reduced infarct size }\end{array}$ & $\begin{array}{l}\text { In vivo: injection } \\
\text { with VEGF-loaded } \\
\text { scaffold [69] }\end{array}$ & $\begin{array}{l}\text { Enhanced microvessel } \\
\text { formation }\end{array}$ \\
\hline & ALLSTAR (NCT01458405) & Ongoing & $\begin{array}{l}\text { In vivo: magnetic-based } \\
\text { delivery [71] }\end{array}$ & $\begin{array}{l}\text { Increased cell retention } \\
\text { and angiogenesis }\end{array}$ \\
\hline & CAREMI [172] & Ongoing & $\begin{array}{c}\text { In vivo: hypoxic } \\
\text { preconditioning [99] }\end{array}$ & $\begin{array}{c}\text { Increased LVEF, } \\
\text { decreased infarction size }\end{array}$ \\
\hline \multirow{2}{*}{ CDCs } & PERSEUS [173] & $\begin{array}{l}\text { Reduced scar size, } \\
\text { improved LVEF }\end{array}$ & $\begin{array}{l}\text { In vivo: encapsulation } \\
\text { into hydrogel [57] }\end{array}$ & $\begin{array}{c}\text { Increased cell retention } \\
\text { and } L V E F \text {, augmented } \\
\text { angiogenesis }\end{array}$ \\
\hline & CADUCEUS [174] & Reduced scar size & $\begin{array}{l}\text { In vivo: magnetic } \\
\text { targeting [72] }\end{array}$ & $\begin{array}{l}\text { Enhanced cell retention } \\
\text { and engraftment, reduced } \\
\text { scar size }\end{array}$ \\
\hline \multirow[t]{2}{*}{ ESCs } & $\begin{array}{l}1 \text { patient (application } \\
\text { of ESC-derived cardiac } \\
\text { progenitors) [9] }\end{array}$ & $\begin{array}{l}\text { Improvement of LVEF } \\
\text { and } 6 \text { min walk distance }\end{array}$ & $\begin{array}{l}\text { In vivo: cells loaded on } \\
\text { fibrin scaffold [175] }\end{array}$ & $\begin{array}{l}\text { Improved cardiac function, } \\
\text { enhanced angiogenesis }\end{array}$ \\
\hline & ESCORT (NCT02057900) & Ongoing (recruiting) & & \\
\hline iPSCs & $\begin{array}{l}\text { Not yet tested in clinical } \\
\text { trials for CVDs }\end{array}$ & & $\begin{array}{l}\text { In vivo: modification with } \\
\text { miR-495 mimic [160] }\end{array}$ & Enhanced angiogenesis \\
\hline
\end{tabular}

CVDs: cardiovascular diseases; HSCs: hematopoietic stem cells; ESCs: endothelial stem cells; CXCR4: C-X-C chemokine receptor 4; VEGF: vascular endothelial growth factor; MSCs: mesenchymal stem cells; LVEF: left ventricular ejection fraction; Rap1: Ras-proximate-1; CSCs: cardiac stem cells; CDCs: cardiospherederived SC; ESCs: embryonic stem cells; iPSCs: induced pluripotent stem cells.

Similar beneficial effects on MSCs survival in vivo and in vitro were induced by overexpression of antiapoptotic genes such as BCL-2 or heat shock proteins [110, 194]. Likewise, IGF-1 transformed MSCs exhibited an increased intracellular level of prosurvival factors, inhibiting cell death after transplantation into ischemic hearts [95, 149]. A lentiviral-mediated overexpression of integrin $\beta 1$ profoundly decreased proapoptotic proteins in MSCs, including caspase 


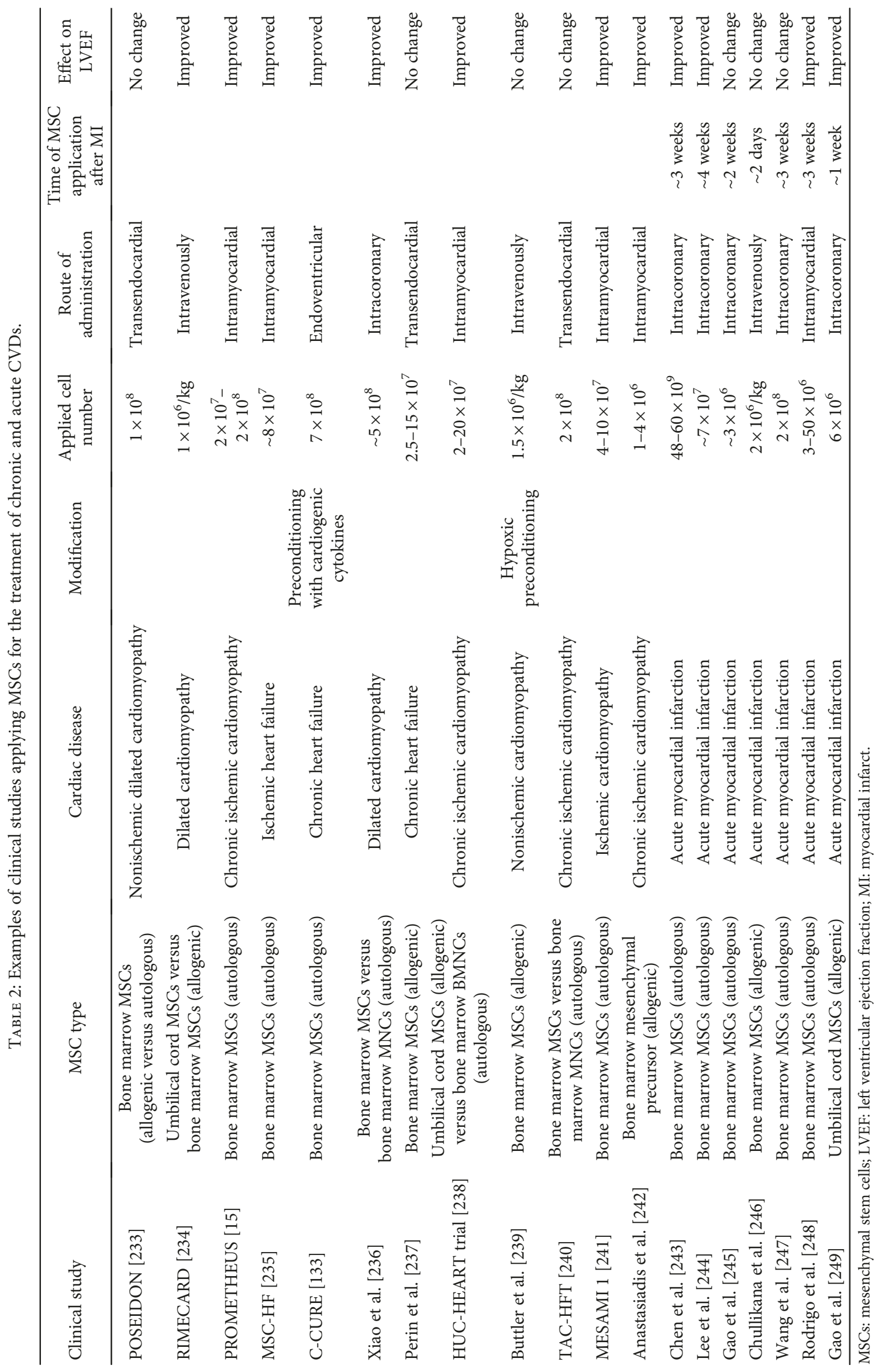


3 and Bax, which, in turn, led to improved cell survival one week after intramyocardial injection into rat heart [143].

Programmed cell death of transplanted MSCs is also triggered by the hypoxic conditions prevailing in the infarcted heart tissue. In particular, HGF-1 was found to increase the resistance of overexpressing MSCs to low oxygen levels and restore heart function in a mouse model [195]. Moreover, miRNA-based reprogramming could improve cell survival. Dakhlallah and coworkers engineered MSCs by introducing miR-133a, which decreased the expression of proapoptotic genes and resulted in a 2-fold improvement of cell engraftment one week after injection in MI-treated rat hearts [155]. In addition, overexpression of miR-1, miR-23a, and miR-210 impede cell death and prolong survival in vivo and in vitro [95].

4.2. Improvement of Adhesion and Engraftment: Induction of Homing Factors and Cell-Matrix Interaction. Once delivered to the damaged heart tissue, the homing and engraftment of MSC is rather low. Since one of the major regulators of SC homing in vivo is the SDF-1/CXCR4 signaling axis, MSCs overexpressing CXCR4 demonstrated a 2 -fold enhancement of their homing capacity when compared to untreated MSCs [196]. In line with this, a higher level of SDF-1 and CXCR4 was observed in protein kinase C overexpressing MSCs, which, in turn, resulted in an increased number of retained cells in infarcted rat hearts that was twice higher compared to control MSCs [190]. Similarly, the stimulation of CXCR4 expression and MSC homing was also documented for interleukin 6 [197].

On the other hand, cell-cell contacts and cell-matrix interactions are important for proper adhesion and engraftment. One group of key molecules mediating cell-matrix adhesion and participating in signal transduction are proteins of the integrin family [198]. Thus, targeting integrinlinked kinase was found to markedly augment homing and regenerative capacity of intracoronary-injected MSCs in minipigs [199]. After two weeks, the authors detected a 4 -fold higher number of MSCs overexpressing integrinlinked kinase [199]. Moreover, a novel promising cytokine that promotes cell engraftment of MSCs was recently identified by Bortolotti and colleagues. They used an in vivo functional screening approach and found that cardiotrophin 1 increased persistence of injected MSCs and preserved cardiac function [200].

Apart from protein overexpression, engraftment of transplanted cells and their homing to injured tissue can be regulated by miRNA-based modifications: for the first purpose, miR-133a, miR-126, miR-34a, and combination of miR-21, miR-24, and miR-221 were reported to be efficient, miR150 , miR-146, and miR-15a/16 - for the latter [155, 201].

4.3. Improvement of Vascularization and Cardiac Remodeling: Induction of Proangiogenic Factors and miRNA. The formation of new blood vessels within the infarcted area is of particular importance for restoring cardiac performance. MSCs can support angiogenesis by the following mechanisms: (1) release of paracrine factors stimulating vessel formation, (2) differentiation into endothelial or vascular smooth muscle cell linage, and (3) acting as perivascular cells [148]. All of these functions can be promoted by suitable cell modification.

VEGF is one of the key factors regulating neovascularization and in vivo studies using VEGF overexpressing MSCs showed improved angiogenic potential by $30 \%$ in rat and mice models [202-204]. Another signaling cascade shown to be crucial in the mediation of the proangiogenic influence of MSCs is phosphoinositide 3-kinase-Akt signaling. Therefore, targeting this pathway by overexpression of VEGF, HGF, or IGF led to improved vascularization, contractility, and reduced infarction size and cardiac remodeling in murine MI models [95, 205].

miRNA-based modification can also be applied to promote the proangiogenic properties of MSCs. Recently, it was shown that transfection of MSCs with miR-146a augments the secretion of VEGF. Compared to the untreated MSCs, animals treated with miR-146a-MSCS exhibited a $50 \%$ lower degree of fibrosis and a significantly enhanced ejection fraction [157]. Likewise, a positive effect on angiogenesis and heart function was shown for the proangiogenic miR-21 and miR-126 [206-208].

In addition, in terms of influencing cardiac remodeling, MSCs engineered to express heme oxygenase- 1 or thioredoxin-1, an antioxidant and regulator of transcription factors and cytokines, displayed increased cardioprotective effects $[209,210]$.

Notably, the concept of cell modification to augment the therapeutic value of MSCs is strongly supported by the C-CURE phase II clinical trial, where priming of hMSCs by a cytokine cocktail was performed in order to obtain cardiopoietic lineage-specified cells [133]. This has proven the safety of cell modification and its feasibility, which also resulted in the initiation of a similar trial CHART-1 (NCT01768702) [171]. At the same time, the impact of genetically modified MSCs on cardiac regeneration has not yet been studied in patients. However, first clinical phase I/II studies of such sort have been established for the treatment of gastrointestinal tumors and lung cancer [211, 212]. In these cases, to induce antitumor effects, MSCs are modified by viral vectors to produce anticancer therapeutics that are released by the cell after homing to the tumor site. For cardiac patients, the safety and benefits of genetic engineering of MSCs still have to be balanced and extensively studied.

4.4. Improvement of MSC-Derived Exosomes: Reduction of Fibrosis and Inflammation. The beneficial paracrine effects of transplanted MSCs are, in part, mediated by the release of exosomes. These are extracellular vesicles $30-100 \mathrm{~nm}$ in diameter, which contain a variety of molecules, including proteins, miRNA, and mRNA, and thereby play an important role in cell-cell communication [213, 214]. Several preclinical studies have demonstrated the benefits of exosome administration in the treatment of CVDs. A reduction of the infarction area by $50 \%$ was achieved when exosomes isolated from MSCs were injected into infarcted rat hearts. In addition, this exosome-based treatment promoted neoangiogenesis by up to $40 \%$ and decreased the infiltration of inflammatory cells into the infarcted ventricular tissue [215]. In vivo 
data obtained by other groups confirmed that MSC-derived exosomes support vessel formation, inhibit the cardiac remodeling process, and preserve pump function of the injured heart [216-219]. Interestingly, in a comparative study, effectiveness of exosomes was found to be superior to MSC injection in a rat model of MI, showing that cardiac fibrosis and inflammation, as well as cardiac performance, were significantly improved in exosome treated hearts [220]. In addition, a meta-analysis by Zhang and colleagues confirmed the benefits of exosome administration on cardiac regeneration [221].

Importantly, cell engineering-based modifications of MSCs have also been demonstrated to favorably influence the cardioprotective properties of released exosomes [222]. This could be used as a tool to further promote the positive outcome of exosome injection. For example, exosomes isolated from Akt overexpressing MSCs induced a 2-fold enhancement of neovascularization in rat hearts which was reflected in a profound improvement of LVEF [223]. Accordingly, in vitro data showed that these exosomes significantly augment the proliferation, migration, and network formation capacity of endothelial cells [223]. In a previously published study, a similar promoting effect on angiogenesis in vivo was described for exosomes derived from MSCs overexpressing hypoxia inducible factor- $1 \alpha$ [224]. Likewise, purified exosomes released from MSCs overexpressing CXCR4, and GATA4, were found to have a higher potential for cardioprotection compared to exosomes derived from normal MSCs [225, 226]. Exosome-mediated cell-free therapy for the treatment of CVDs has not been applied in clinical trials yet. However, phase I/II studies for cancer therapy using exosomes already confirmed its general safety [219, 227].

\section{Conclusion}

The strategy of using SCs for the treatment of CVDs was considered to be the most promising approach for heart regeneration, intended to complement or replace currently existing clinic treatment options. Indeed, numerous preclinical studies have demonstrated the strong regenerative potential of SCs. However, due to the inconsistent results from clinical trials and the low efficiency of transplanted SCs, this concept could not fully meet the expectations and be widely integrated into clinical practice. Since the therapeutic potential of SCs is undisputable, researchers have made considerable effort to significantly improve the effectiveness of SCs by the generation of modified cell products.

Although the efficiency of modified SCs has been shown to be superior to unmodified cells in vitro and in vivo, most studies focused on one single strategy to improve the therapeutic outcome. However, cardiovascular disorders are complex diseases with multiple mechanisms involved in pathogenesis. Therefore, curative concepts with complex activity are required. Thus, while improving cell-based therapeutics, it is crucial to take into account that multiple features should be facilitated simultaneously. For example, it is not sufficient to improve cell survival or retention, but also, a profound proangiogenic and cardioprotective activity should be ensured, and age-related decline of SC efficiency should be eliminated. Several strategies could be used to follow this principle, including genetic cell modification, cytokine preconditioning, and pharmacological treatments or their hybrids.

In order to achieve the highest possible outcome in SC treatment, a system of patient's response predictors should be developed. It has been previously shown that patients with worse baseline condition responded to bone marrow-derived mononuclear cell therapy, whereas others with better health condition did not $[228,229]$. Therefore, a system is required that allows classification and selection of patients matching cell therapeutics. Plasma profiling of patients could help to find novel biomarkers that identify responders and nonresponders [230]. Recently, in the phase III PERFECT clinical trial, the nonresponse on endothelial progenitor cell administration was found to be associated with the expression of SH2B3 protein [165].

To summarize, the whole concept of SC modification has already been proven to be feasible and safe in clinical trials using MSCs [231, 232]. Extensive work is still needed to generate powerful off-the-shelf SC therapeutics. Together with personalized cell-based therapy (e.g., responders versus nonresponders), SCs might fulfill the expectations of novel curative options for cardiac patients.

\section{Disclosure}

Natalia Voronina's current address is Division of Molecular Genetics, German Cancer Research Center (DKFZ), Im Neuenheimer Feld 580, 69120 Heidelberg, Germany, a foundation under public law.

\section{Conflicts of Interest}

The authors declare no conflict of interest regarding the publication of this article.

\section{Authors' Contributions}

Heiko Lemcke and Natalia Voronina contributed equally to this work.

\section{Acknowledgement}

The authors thank Dr. Ulrike Ruch and Dr. Cornelia Lux for their constructive comments and help during the manuscript preparation. This work was supported by the German Federal Ministry of Education and Research (FKZ 0312138A and FKZ 316159), the State Mecklenburg-Western Pomerania with ESF (ESF/IVWM-B34-0030/10 and ESF/IVBM-B350010/12), and the DFG (DA1296-1). In addition, Robert David is supported by the FORUN Program of Rostock University Medical Centre (889001), the DAMP Foundation, and the BMBF (VIP+ 00240). Heiko Lemcke is supported by the FORUN Program of Rostock University Medical Centre (889006) and the Käthe und Josef Klinz Foundation (T319/29737/2017). 


\section{References}

[1] GBD 2013 Risk Factors Collaborators, M. H. Forouzanfar, L. Alexander et al., "Global, regional, and national comparative risk assessment of 79 behavioural, environmental and occupational, and metabolic risks or clusters of risks in 188 countries, 1990-2013: a systematic analysis for the Global Burden of Disease Study 2013," Lancet, vol. 386, no. 10010, pp. 2287-2323, 2015.

[2] C. H. Chen, K. I. Sereti, B. M. Wu, and R. Ardehali, "Translational aspects of cardiac cell therapy," Journal of Cellular and Molecular Medicine, vol. 19, no. 8, pp. 1757-1772, 2015.

[3] N. J. Pagidipati and T. A. Gaziano, "Estimating deaths from cardiovascular disease: a review of global methodologies of mortality measurement," Circulation, vol. 127, no. 6, pp. 749-756, 2013.

[4] D. Mozaffarian, E. J. Benjamin, A. S. Go et al., "Heart disease and stroke statistics-2015 update: a report from the American Heart Association," Circulation, vol. 131, no. 4, pp. e29-e322, 2015.

[5] O. Bergmann, R. D. Bhardwaj, S. Bernard et al., "Evidence for cardiomyocyte renewal in humans," Science, vol. 324, no. 5923, pp. 98-102, 2009.

[6] A. Behfar, R. Crespo-Diaz, A. Terzic, and B. J. Gersh, "Cell therapy for cardiac repair-lessons from clinical trials," Nature Reviews Cardiology, vol. 11, no. 4, pp. 232-246, 2014.

[7] J. B. Kostis, "The importance of managing hypertension and dyslipidemia to decrease cardiovascular disease," Cardiovascular Drugs and Therapy, vol. 21, no. 4, pp. 297-309, 2007.

[8] D. Mason, Y.-Z. Chen, H. V. Krishnan, and S. Sant, "Cardiac gene therapy: recent advances and future directions," Journal of Controlled Release, vol. 215, pp. 101-111, 2015.

[9] P. Menasché, V. Vanneaux, A. Hagège et al., "Human embryonic stem cell-derived cardiac progenitors for severe heart failure treatment: first clinical case report," European Heart Journal, vol. 36, no. 30, pp. 2011-2017, 2015.

[10] N. J. Leeper, A. L. Hunter, and J. P. Cooke, "Stem cell therapy for vascular regeneration: adult, embryonic, and induced pluripotent stem cells," Circulation, vol. 122, no. 5, pp. 517-526, 2010.

[11] P. A. Lalit, D. J. Hei, A. N. Raval, and T. J. Kamp, "Induced pluripotent stem cells for post-myocardial infarction repair: remarkable opportunities and challenges," Circulation Research, vol. 114, no. 8, pp. 1328-1345, 2014.

[12] C. Mora, M. Serzanti, A. Consiglio, M. Memo, and P. Dell'Era, "Clinical potentials of human pluripotent stem cells," Cell Biology and Toxicology, vol. 33, no. 4, pp. 351360, 2017.

[13] M. Nishio, M. Nakahara, A. Yuo, and K. Saeki, "Human pluripotent stem cells: towards therapeutic development for the treatment of lifestyle diseases," World Journal of Stem Cells, vol. 8, no. 2, pp. 56-61, 2016.

[14] M. R. Rosen, R. J. Myerburg, D. P. Francis, G. D. Cole, and E. Marbán, "Translating stem cell research to cardiac disease therapies," Journal of the American College of Cardiology, vol. 64, no. 9, pp. 922-937, 2014.

[15] V. Karantalis, D. L. DiFede, G. Gerstenblith et al., "Autologous mesenchymal stem cells produce concordant improvements in regional function, tissue perfusion, and fibrotic burden when administered to patients undergoing coronary artery bypass grafting: the prospective randomized study of mesenchymal stem cell therapy in patients undergoing cardiac surgery (PROMETHEUS) trial," Circulation Research, vol. 114, no. 8, pp. 1302-1310, 2014.

[16] E. C. Perin, R. Sanz-Ruiz, P. L. Sánchez et al., "Adiposederived regenerative cells in patients with ischemic cardiomyopathy: the PRECISE trial," American Heart Journal, vol. 168, no. 1, pp. 88-95.e2, 2014.

[17] A. R. Chugh, G. M. Beache, J. H. Loughran et al., "Administration of cardiac stem cells in patients with ischemic cardiomyopathy: the SCIPIO trial: surgical aspects and interim analysis of myocardial function and viability by magnetic resonance," Circulation, vol. 126, no. 11, Supplement 1, pp. S54-S64, 2012.

[18] M. H. Yacoub and J. Terrovitis, "CADUCEUS, SCIPIO, ALCADIA: cell therapy trials using cardiac-derived cells for patients with post myocardial infarction LV dysfunction, still evolving," Global Cardiology Science and Practice, vol. 2013, no. 1, pp. 5-8, 2013.

[19] K. Zhu, J. Li, Y. Wang et al., "Intramyocardial autologous bone marrow-derived stem cells injection for ischemic heart disease ineligible for revascularization: a systematic review and meta-analysis," Archives of Medical Research, vol. 46, no. 4, pp. 286-295, 2015.

[20] L. Luo, J. Tang, K. Nishi et al., "Fabrication of synthetic mesenchymal stem cells for the treatment of acute myocardial infarction in mice," Circulation Researchax, vol. 120, no. 11, pp. 1768-1775, 2017.

[21] J. Tang, D. Shen, T. G. Caranasos et al., "Therapeutic microparticles functionalized with biomimetic cardiac stem cell membranes and secretome," Nature Communications, vol. 8, article 13724, 2017.

[22] M. M. Monsanto, B. J. Wang, and M. A. Sussman, "Synthetic MSC? Nothing beats the real thing," Circulation Research, vol. 120, no. 11, pp. 1694-1695, 2017.

[23] P. J. Kim, M. Mahmoudi, X. Ge et al., "Direct evaluation of myocardial viability and stem cell engraftment demonstrates salvage of the injured myocardium," Circulation Research, vol. 116, no. 7, pp. e40-e50, 2015.

[24] S. Golpanian, J. El-Khorazaty, A. Mendizabal et al., "Effect of aging on human mesenchymal stem cell therapy in ischemic cardiomyopathy patients," Journal of the American College of Cardiology, vol. 65, no. 2, pp. 125-132, 2015.

[25] L. Zeng, Q. Hu, X. Wang et al., "Bioenergetic and functional consequences of bone marrow-derived multipotent progenitor cell transplantation in hearts with postinfarction left ventricular remodeling," Circulation, vol. 115, no. 14, pp. 1866-1875, 2007.

[26] N. Dib, H. Khawaja, S. Varner, M. McCarthy, and A. Campbellv, "Cell therapy for cardiovascular disease: a comparison of methods of delivery," Journal of Cardiovascular Translational Research, vol. 4, no. 2, pp. 177-181, 2011.

[27] J. Terrovitis, R. Lautamäki, M. Bonios et al., "Noninvasive quantification and optimization of acute cell retention by in vivo positron emission tomography after intramyocardial cardiac-derived stem cell delivery," Journal of the American College of Cardiology, vol. 54, no. 17, pp. 1619-1626, 2009.

[28] T. E. Robey, M. K. Saiget, H. Reinecke, and C. E. Murry, "Systems approaches to preventing transplanted cell death in cardiac repair," Journal of Molecular and Cellular Cardiology, vol. 45, no. 4, pp. 567-581, 2008.

[29] M. Zhang, D. Methot, V. Poppa, Y. Fujio, K. Walsh, and C. E. Murry, "Cardiomyocyte grafting for cardiac repair: graft cell 
death and anti-death strategies," Journal of Molecular and Cellular Cardiology, vol. 33, no. 5, pp. 907-921, 2001.

[30] A. Skorska, P. Müller, R. Gaebel et al., "GMP-conformant on-site manufacturing of a CD133+ stem cell product for cardiovascular regeneration," Stem Cell Research \& Therapy, vol. 8, no. 1, p. 33, 2017.

[31] R. Sanz-Ruiz and F. Fernández-Avilés, "Autologous and allogeneic cardiac stem cell therapy for cardiovascular diseases," Pharmacological Research, vol. 127, pp. 92-100, 2018.

[32] A. P. Beltrami, L. Barlucchi, D. Torella et al., "Adult cardiac stem cells are multipotent and support myocardial regeneration," Cell, vol. 114, no. 6, pp. 763-776, 2003.

[33] M. M. Monsanto, K. S. White, T. Kim et al., "Concurrent isolation of 3 distinct cardiac stem cell populations from a single human heart biopsy," Circulation Research, vol. 121, no. 2, pp. 113-124, 2017.

[34] J. J. Tan, C. A. Carr, D. J. Stuckey et al., "Isolation and expansion of cardiosphere-derived stem cells," Current Protocols in Stem Cell Biology, vol. 16, pp. 2C.3.1-2C.3.12, 2011.

[35] E. Messina, L. De Angelis, G. Frati et al., "Isolation and expansion of adult cardiac stem cells from human and murine heart," Circulation Research, vol. 95, no. 9, pp. 911$921,2004$.

[36] S. T. Lee, A. J. White, S. Matsushita et al., "Intramyocardial injection of autologous cardiospheres or cardiospherederived cells preserves function and minimizes adverse ventricular remodeling in pigs with heart failure postmyocardial infarction," Journal of the American College of Cardiology, vol. 57, no. 4, pp. 455-465, 2011.

[37] R. Gallet, E. Tseliou, J. Dawkins et al., "Intracoronary delivery of self-assembling heart-derived microtissues (cardiospheres) for prevention of adverse remodeling in a pig model of convalescent myocardial infarction," Circulation: Cardiovascular Interventions, vol. 8, no. 5, article e002391, 2015.

[38] C. J. Kapelios, J. N. Nanas, and K. Malliaras, "Allogeneic cardiosphere-derived cells for myocardial regeneration: current progress and recent results," Future Cardiology, vol. 12, no. 1, pp. 87-100, 2016.

[39] R. R. Makkar, R. R. Smith, K. Cheng et al., "Intracoronary cardiosphere-derived cells for heart regeneration after myocardial infarction (CADUCEUS): a prospective, randomised phase 1 trial," Lancet, vol. 379, no. 9819, pp. 895904, 2012.

[40] K. Ban, S. Bae, and Y. Yoon, "Current strategies and challenges for purification of cardiomyocytes derived from human pluripotent stem cells," Theranostics, vol. 7, no. 7, pp. 2067-2077, 2017.

[41] J. J. Jung, B. Husse, C. Rimmbach et al., "Programming and isolation of highly pure physiologically and pharmacologically functional sinus-nodal bodies from pluripotent stem cells," Stem Cell Reports, vol. 2, no. 5, pp. 592-605, 2014.

[42] S. J. Kattman, A. D. Witty, M. Gagliardi et al., "Stage-specific optimization of activin/nodal and BMP signaling promotes cardiac differentiation of mouse and human pluripotent stem cell lines," Cell Stem Cell, vol. 8, no. 2, pp. 228-240, 2011.

[43] N. C. Dubois, A. M. Craft, P. Sharma et al., "SIRPA is a specific cell-surface marker for isolating cardiomyocytes derived from human pluripotent stem cells," Nature Biotechnology, vol. 29, no. 11, pp. 1011-1018, 2011.

[44] S. I. Protze, J. Liu, U. Nussinovitch et al., "Sinoatrial node cardiomyocytes derived from human pluripotent cells function as a biological pacemaker," Nature Biotechnology, vol. 35, no. 1, pp. 56-68, 2016.

[45] R. J. P. Skelton, T. J. Kamp, D. A. Elliott, and R. Ardehali, "Biomarkers of human pluripotent stem cell-derived cardiac lineages," Trends in Molecular Medicine, vol. 23, no. 7, pp. 651-668, 2017.

[46] S. Tohyama, F. Hattori, M. Sano et al., "Distinct metabolic flow enables large-scale purification of mouse and human pluripotent stem cell-derived cardiomyocytes," Cell Stem Cell, vol. 12, no. 1, pp. 127-137, 2013.

[47] M. Fuerstenau-Sharp, M. E. Zimmermann, K. Stark et al., "Generation of highly purified human cardiomyocytes from peripheral blood mononuclear cell-derived induced pluripotent stem cells," PLoS One, vol. 10, no. 5, article e0126596, 2015.

[48] P. Huang, X. Tian, Q. Li, and Y. Yang, "New strategies for improving stem cell therapy in ischemic heart disease," Heart Failure Reviews, vol. 21, no. 6, pp. 737-752, 2016.

[49] C. Lang, S. Lehner, A. Todica et al., "In-vivo comparison of the acute retention of stem cell derivatives and fibroblasts after intramyocardial transplantation in the mouse model," European Journal of Nuclear Medicine and Molecular Imaging, vol. 41, no. 12, pp. 2325-2336, 2014.

[50] V. F. Forest, A. M. Tirouvanziam, C. Perigaud et al., "Cell distribution after intracoronary bone marrow stem cell delivery in damaged and undamaged myocardium: implications for clinical trials," Stem Cell Research \& Therapy, vol. 1, no. 1, p. 4, 2010.

[51] I. M. Barbash, P. Chouraqui, J. Baron et al., "Systemic delivery of bone marrow-derived mesenchymal stem cells to the infarcted myocardium: feasibility, cell migration, and body distribution," Circulation, vol. 108, no. 7, pp. 863-868, 2003.

[52] F. van den Akker, D. M. Feyen, P. van den Hoogen et al., "Intramyocardial stem cell injection: go(ne) with the flow," European Heart Journal, vol. 38, pp. ehw056-ehw186, 2016.

[53] T. Freyman, G. Polin, H. Osman et al., "A quantitative, randomized study evaluating three methods of mesenchymal stem cell delivery following myocardial infarction," European Heart Journal, vol. 27, no. 9, pp. 1114-1122, 2006.

[54] C. Lang, S. Lehner, A. Todica et al., "Positron emission tomography based in-vivo imaging of early phase stem cell retention after intramyocardial delivery in the mouse model," European Journal of Nuclear Medicine and Molecular Imaging, vol. 40, no. 11, pp. 1730-1738, 2013.

[55] J. Tongers, D. W. Losordo, and U. Landmesser, "Stem and progenitor cell-based therapy in ischaemic heart disease: promise, uncertainties, and challenges," European Heart Journal, vol. 32, no. 10, pp. 1197-1206, 2011.

[56] S. Taghavi, J. M. Duran, R. M. Berretta et al., "Validation of transcatheter left ventricular electromechanical mapping for assessment of cardiac function and targeted transendocardial injection in a porcine ischemia-reperfusion model," American Journal of Translational Research, vol. 4, no. 2, pp. 240-246, 2012.

[57] A. E. Mayfield, E. L. Tilokee, N. Latham et al., "The effect of encapsulation of cardiac stem cells within matrix-enriched hydrogel capsules on cell survival, post-ischemic cell retention and cardiac function," Biomaterials, vol. 35 , no. 1, pp. 133-142, 2014.

[58] R. R. Smith, E. Marbán, and L. Marbán, "Enhancing retention and efficacy of cardiosphere-derived cells administered after 
myocardial infarction using a hyaluronan-gelatin hydrogel," Biomatter, vol. 3, no. 1, article e24490, 2013.

[59] A. Omotuyi and J. Fakoya, "New delivery systems of stem cells for vascular regeneration in ischemia," Frontiers in Cardiovascular Medicine, vol. 4, pp. 1-20, 2017.

[60] R. Gaetani, D. A. M. Feyen, V. Verhage et al., "Epicardial application of cardiac progenitor cells in a 3D-printed gelatin/hyaluronic acid patch preserves cardiac function after myocardial infarction," Biomaterials, vol. 61, pp. 339-348, 2015.

[61] D. A. M. Feyen, R. Gaetani, P. A. Doevendans, and J. P. G. Sluijter, "Stem cell-based therapy: improving myocardial cell delivery," Advanced Drug Delivery Reviews, vol. 106, Part A, pp. 104-115, 2016.

[62] R. Madonna, L. Petrov, M. A. Teberino et al., "Transplantation of adipose tissue mesenchymal cells conjugated with VEGF-releasing microcarriers promotes repair in murine myocardial infarction," Cardiovascular Research, vol. 108, no. 1, pp. 39-49, 2015.

[63] X. Li, K. Tamama, X. Xie, and J. Guan, "Improving cell engraftment in cardiac stem cell therapy," Stem Cells International, vol. 2016, Article ID 7168797, 11 pages, 2016.

[64] R. R. Mallepally, C. C. Parrish, M. A. M. Mc Hugh, and K. R. Ward, "Hydrogen peroxide filled poly(methyl methacrylate) microcapsules: potential oxygen delivery materials," International Journal of Pharmaceutics, vol. 475, no. 1-2, pp. 130137, 2014.

[65] S. I. H. Abdi, S. M. Ng, and J. O. Lim, "An enzyme-modulated oxygen-producing micro-system for regenerative therapeutics," International Journal of Pharmaceutics, vol. 409, no. 1-2, pp. 203-205, 2011.

[66] X. Zhang, H. Wang, X. Ma et al., "Preservation of the cardiac function in infarcted rat hearts by the transplantation of adipose-derived stem cells with injectable fibrin scaffolds," Experimental Biology and Medicine, vol. 235, no. 12, pp. 1505-1515, 2010.

[67] D. L. Simpson and S. C. Dudley, "Modulation of human mesenchymal stem cell function in a three-dimensional matrix promotes attenuation of adverse remodelling after myocardial infarction," Journal of Tissue Engineering and Regenerative Medicine, vol. 7, no. 3, pp. 192-202, 2013.

[68] K. L. Kim, D. K. Han, K. Park et al., "Enhanced dermal wound neovascularization by targeted delivery of endothelial progenitor cells using an RGD-g-PLLA scaffold," Biomaterials, vol. 30, no. 22, pp. 3742-3748, 2009.

[69] H. J. Chung, J. T. Kim, H. J. Kim et al., "Epicardial delivery of VEGF and cardiac stem cells guided by 3 -dimensional PLLA mat enhancing cardiac regeneration and angiogenesis in acute myocardial infarction," Journal of Controlled Release, vol. 205, pp. 218-230, 2015.

[70] P. Hitscherich, S. Wu, R. Gordan, L. H. Xie, T. Arinzeh, and E. J. Lee, "The effect of PVDF-TrFE scaffolds on stem cell derived cardiovascular cells," Biotechnology and Bioengineering, vol. 113, no. 7, pp. 1577-1585, 2016.

[71] A. C. Vandergriff, T. M. Hensley, E. T. Henry et al., "Magnetic targeting of cardiosphere-derived stem cells with ferumoxytol nanoparticles for treating rats with myocardial infarction," Biomaterials, vol. 35, no. 30, pp. 8528-8539, 2014.

[72] K. Cheng, T. S. Li, K. Malliaras, D. R. Davis, Y. Zhang, and E. Marbán, "Magnetic targeting enhances engraftment and functional benefit of iron-labeled cardiosphere-derived cells in myocardial infarction," Circulation Research, vol. 106, no. 10, pp. 1570-1581, 2010.

[73] K. Cheng, K. Malliaras, T. S. Li et al., "Magnetic enhancement of cell retention, engraftment, and functional benefit after intracoronary delivery of cardiac-derived stem cells in a rat model of ischemia/reperfusion," Cell Transplantation, vol. 21, no. 6, pp. 1121-1135, 2012.

[74] Y. Shen, X. Liu, Z. Huang et al., "Comparison of magnetic intensities for mesenchymal stem cell targeting therapy on ischemic myocardial repair: high magnetic intensity improves cell retention but has no additional functional benefit," Cell Transplantation, vol. 24, no. 10, pp. 1981-1997, 2015.

[75] K. Cheng, D. Shen, M. T. Hensley et al., "Magnetic antibodylinked nanomatchmakers for therapeutic cell targeting," Nature Communications, vol. 5, p. 4880, 2014.

[76] P. Hua, Y.-Y. Wang, L.-B. Liu et al., "In vivo magnetic resonance imaging tracking of transplanted superparamagnetic iron oxide-labeled bone marrow mesenchymal stem cells in rats with myocardial infarction," Molecular Medicine Reports, vol. 11, no. 1, pp. 113-120, 2015.

[77] M. R. Santoso and P. C. Yang, "Magnetic nanoparticles for targeting and imaging of stem cells in myocardial infarction," Stem Cells International, vol. 2016, Article ID 4198790, 9 pages, 2016.

[78] A. Blocki, S. Beyer, J. Y. Dewavrin et al., "Microcapsules engineered to support mesenchymal stem cell (MSC) survival and proliferation enable long-term retention of MSCs in infarcted myocardium," Biomaterials, vol. 53, pp. 12-24, 2015.

[79] R. G. Gomez-Mauricio, A. Acarregui, F. M. SánchezMargallo et al., "A preliminary approach to the repair of myocardial infarction using adipose tissue-derived stem cells encapsulated in magnetic resonance-labelled alginate microspheres in a porcine model," European Journal of Pharmaceutics and Biopharmaceutics, vol. 84, no. 1, pp. 29-39, 2013.

[80] P. Müller, R. Gaebel, H. Lemcke et al., "Intramyocardial fate and effect of iron nanoparticles co-injected with MACS ${ }^{\circledR}$ purified stem cell products," Biomaterials, vol. 135, pp. 7484, 2017.

[81] N. Voronina, H. Lemcke, F. Wiekhorst, J.-P. Kühn, G. Steinhoff, and R. David, "Non-viral magnetic engineering of endothelial cells with microRNA and plasmid-DNA - an optimized targeting approach," Nanomedicine: Nanotechnology, Biology and Medicine, vol. 12, no. 8, pp. 2353-2364, 2016.

[82] P. Müller, N. Voronina, F. Hausburg et al., "Magnet-bead based microRNA delivery system to modify CD133+ stem cells," Stem Cells International, vol. 2016, pp. 1-16, 2016.

[83] S. V. Rojas, M. Meier, R. Zweigerdt et al., "Multimodal imaging for in vivo evaluation of induced pluripotent stem cells in a murine model of heart failure," Artificial Organs, vol. 41, no. 2, pp. 192-199, 2017.

[84] L. H. A. Silva, F. F. Cruz, M. M. Morales, D. J. Weiss, and P. R. M. Rocco, "Magnetic targeting as a strategy to enhance therapeutic effects of mesenchymal stromal cells," Stem Cell Res Ther, vol. 8, no. 1, p. 58, 2017.

[85] W. W. Albuquerque, R. M. Costa, S. Fernandes Tde, and A. L. Porto, "Evidences of the static magnetic field influence on cellular systems," Progress in Biophysics and Molecular Biology, vol. 121, no. 1, pp. 16-28, 2016. 
[86] J. E. Bae, M. I. Huh, B. K. Ryu et al., "The effect of static magnetic fields on the aggregation and cytotoxicity of magnetic nanoparticles," Biomaterials, vol. 32, no. 35, pp. 9401-9414, 2011.

[87] A. V. Naumova, N. Balu, V. L. Yarnykh, H. Reinecke, C. E. Murry, and C. Yuan, "Magnetic resonance imaging tracking of graft survival in the infarcted heart: iron oxide particles versus ferritin overexpression approach," Journal of Cardiovascular Pharmacology and Therapeutics, vol. 19, no. 4, pp. 358-367, 2014.

[88] C. W. Lee, S. I. Choi, S. J. Lee et al., "The effectiveness of ferritin as a contrast agent for cell tracking MRI in mouse cancer models," Yonsei Medical Journal, vol. 58, no. 1, pp. 51-58, 2017.

[89] I. K. Cho, S. Wang, H. Mao, and A. W. Chan, "Genetic engineered molecular imaging probes for applications in cell therapy: emphasis on MRI approach," American Journal of Nuclear Medicine and Molecular Imaging, vol. 6, no. 5, pp. 234-261, 2016.

[90] C. Toma, A. Fisher, J. Wang et al., "Vascular endoluminal delivery of mesenchymal stem cells using acoustic radiation force," Tissue Engineering Part A, vol. 17, no. 9-10, pp. 1457-1464, 2011.

[91] J. Tong, J. Ding, X. Shen et al., "Mesenchymal stem cell transplantation enhancement in myocardial infarction rat model under ultrasound combined with nitric oxide microbubbles," PLoS One, vol. 8, no. 11, article e80186, 2013.

[92] X. Chang, J. Liu, X. Liao, and G. Liu, "Ultrasound-mediated microbubble destruction enhances the therapeutic effect of intracoronary transplantation of bone marrow stem cells on myocardial infarction," International Journal of Clinical and Experimental Pathology, vol. 8, no. 2, pp. 2221-2234, 2015.

[93] L. Woudstra, P. A. J. Krijnen, S. J. P. Bogaards et al., "Development of a new therapeutic technique to direct stem cells to the infarcted heart using targeted microbubbles: StemBells," Stem Cell Research, vol. 17, no. 1, pp. 6-15, 2016.

[94] E. Nollet, V. Y. Hoymans, A. H. Van Craenenbroeck, C. J. Vrints, and E. M. Van Craenenbroeck, "Improving stem cell therapy in cardiovascular diseases: the potential role of microRNA," American Journal of Physiology - Heart and Circulatory Physiology, vol. 311, no. 1, pp. H207-H218, 2016.

[95] A. A. Karpov, D. V. Udalova, M. G. Pliss, and M. M. Galagudza, "Can the outcomes of mesenchymal stem cell-based therapy for myocardial infarction be improved? Providing weapons and armour to cells," Cell Proliferation, vol. 50, no. 2, 2017.

[96] C. Dall, M. Khan, C. A. Chen, and M. G. Angelos, "Oxygen cycling to improve survival of stem cells for myocardial repair: a review," Life Sciences, vol. 153, pp. 124-131, 2016.

[97] Y. SP, Z. Wei, and L. Wei, "Preconditioning strategy in stem cell transplantation therapy," Translational Stroke Research, vol. 4, no. 1, pp. 76-88, 2013.

[98] X. Hu, Y. SP, J. L. Fraser et al., "Transplantation of hypoxiapreconditioned mesenchymal stem cells improves infarcted heart function via enhanced survival of implanted cells and angiogenesis," The Journal of Thoracic and Cardiovascular Surgery, vol. 135, no. 4, pp. 799-808, 2008.

[99] T. Hosoyama, M. Samura, T. Kudo et al., "Cardiospherederived cell sheet primed with hypoxia improves left ventricular function of chronically infarcted heart," American Journal of Translational Research, vol. 7, no. 12, pp. 27382751, 2015.
[100] M. Kubo, T. S. Li, R. Suzuki et al., "Hypoxic preconditioning increases survival and angiogenic potency of peripheral blood mononuclear cells via oxidative stress resistance," AJP: Heart and Circulatory Physiology, vol. 294, no. 2, pp. H590-H595, 2008.

[101] J. Jaussaud, M. Biais, J. Calderon et al., "Hypoxia-preconditioned mesenchymal stromal cells improve cardiac function in a swine model of chronic myocardial ischaemia," European Journal of Cardio-Thoracic Surgery, vol. 43, no. 5, pp. 10501057, 2013.

[102] L. Li, P. K. Jaiswal, G. Makhoul et al., "Hypoxia modulates cell migration and proliferation in placenta-derived mesenchymal stem cells," The Journal of Thoracic and Cardiovascular Surgery, vol. 154, no. 2, pp. 543-552.e3, 2017.

[103] D. S. Kim, Y. J. Ko, M. W. Lee et al., "Effect of low oxygen tension on the biological characteristics of human bone marrow mesenchymal stem cells," Cell Stress Chaperones, vol. 21, no. 6, pp. 1089-1099, 2016.

[104] Y. L. Tang, W. Zhu, M. Cheng et al., "Hypoxic preconditioning enhances the benefit of cardiac progenitor cell therapy for treatment of myocardial infarction by inducing CXCR4 expression," Circulation Research, vol. 104, no. 10, pp. 1209-1216, 2009.

[105] H. Liu, S. Liu, Y. Li et al., "The role of SDF-1-CXCR4/CXCR7 axis in the therapeutic effects of hypoxia-preconditioned mesenchymal stem cells for renal ischemia/reperfusion injury," PLoS One, vol. 7, no. 4, article e34608, 2012.

[106] A. A. Calinescu, V. N. Yadav, E. Carballo et al., "Survival and proliferation of neural progenitor-derived glioblastomas under hypoxic stress is controlled by a CXCL12/CXCR4 autocrine-positive feedback mechanism," Clinical Cancer Research, vol. 23, no. 5, pp. 1250-1262, 2017.

[107] Z. Chen, X. Pan, Y. Yao et al., "Regulation of c-kit+ progenitor cells by stromal cell derived factor- $1 \alpha$ in adult murine heart," Heart, Lung and Circulation, vol. 23, no. 1, pp. 7581, 2014.

[108] X. Guo, S. Xu, X. Gao et al., "Macrophage migration inhibitory factor promotes vasculogenic mimicry formation induced by hypoxia via CXCR4/AKT/EMT pathway in human glioblastoma cells," Oncotarget, vol. 8, pp. 8035880372, 2017.

[109] S. L. Stubbs, S. T.-F. Hsiao, H. M. Peshavariya, S. Y. Lim, G. J. Dusting, and R. J. Dilley, "Hypoxic preconditioning enhances survival of human adipose-derived stem cells and conditions endothelial cells in vitro," Stem Cells and Development, vol. 21, no. 11, pp. 1887-1896, 2012.

[110] S. Der Sarkissian, T. Lévesque, and N. Noiseux, "Optimizing stem cells for cardiac repair: current status and new frontiers in regenerative cardiology," World Journal of Stem Cells, vol. 9, no. 1, pp. 9-25, 2017.

[111] H. Drolle, M. Wagner, J. Vasold et al., "Hypoxia regulates proliferation of acute myeloid leukemia and sensitivity against chemotherapy," Leukemia Research, vol. 39, no. 7, pp. 779-785, 2015.

[112] Y. Fan, L. Wang, C. Liu et al., "Local renin-angiotensin system regulates hypoxia-induced vascular endothelial growth factor synthesis in mesenchymal stem cells," International Journal Of Clinical And Experimental Pathology, vol. 8, no. 3, pp. 2505-2514, 2015.

[113] C. Zhu, J. Yu, Q. Pan et al., "Hypoxia-inducible factor-2 alpha promotes the proliferation of human placenta-derived 
mesenchymal stem cells through the MAPK/ERK signaling pathway," Scientific Reports, vol. 6, no. 1, article 35489, 2016.

[114] M. Z. Ratajczak and M. Suszynska, "Emerging strategies to enhance homing and engraftment of hematopoietic stem cells," Stem Cell Reviews and Reports, vol. 12, no. 1, pp. 121-128, 2016.

[115] M. Ali, A. Mehmood, M. S. Anjum, M. N. Tarrar, S. N. Khan, and S. Riazuddin, "Diazoxide preconditioning of endothelial progenitor cells from streptozotocin-induced type 1 diabetic rats improves their ability to repair diabetic cardiomyopathy," Molecular and Cellular Biochemistry, vol. 410, no. 1-2, pp. 267-279, 2015.

[116] I. Khan, A. Ali, M. A. Akhter et al., "Epac-Rap1-activated mesenchymal stem cells improve cardiac function in rat model of myocardial infarction," Cardiovascular Therapeutics, vol. 35, no. 2, 2017.

[117] D. Han, X. Li, W.-S. Fan et al., "Activation of cannabinoid receptor type II by AM1241 protects adipose-derived mesenchymal stem cells from oxidative damage and enhances their therapeutic efficacy in myocardial infarction mice via Stat3 activation," Oncotarget, vol. 8, no. 39, 2017.

[118] C. Toma, "Human mesenchymal stem cells differentiate to a cardiomyocyte phenotype in the adult murine heart," Circulation, vol. 105, no. 1, pp. 93-98, 2002.

[119] H. C. Quevedo, K. E. Hatzistergos, B. N. Oskouei et al., "Allogeneic mesenchymal stem cells restore cardiac function in chronic ischemic cardiomyopathy via trilineage differentiating capacity," Proceedings of the National Academy of Sciences, vol. 106, no. 33, pp. 14022-14027, 2009.

[120] H. Lemcke, R. Gaebel, A. Skorska et al., "Mechanisms of stem cell based cardiac repair - gap junctional signaling promotes the cardiac lineage specification of mesenchymal stem cells," Scientific Reports, vol. 7, no. 1, p. 9755, 2017.

[121] S. Shi, X. Wu, X. Wang et al., "Differentiation of bone marrow mesenchymal stem cells to cardiomyocyte-like cells is regulated by the combined low dose treatment of transforming growth factor- $\beta 1$ and 5 -azacytidine," Stem Cells International, vol. 2016, Article ID 3816256, 11 pages, 2016.

[122] J. Li, K. Zhu, Y. Wang et al., "Combination of IGF-1 gene manipulation and 5-AZA treatment promotes differentiation of mesenchymal stem cells into cardiomyocyte-like cells," Molecular Medicine Reports, vol. 11, no. 2, pp. 815-820, 2015.

[123] A. Piryaei, M. Soleimani, M. H. Heidari, M. Saheli, R. Rohani, and M. Almasieh, "Ultrastructural maturation of human bone marrow mesenchymal stem cells-derived cardiomyocytes under alternative induction of 5-azacytidine," Cell Biol Int, vol. 39, no. 5, pp. 519-530, 2015.

[124] S. Khajeniazi, M. Solati, Y. Yazdani, M. Soleimani, and A. Kianmehr, "Synergistic induction of cardiomyocyte differentiation from human bone marrow mesenchymal stem cells by interleukin $1 \beta$ and 5-azacytidine," Biological Chemistry, vol. 397, no. 12, pp. 1355-1364, 2016.

[125] G. W. Zhang, G. TX, X. Y. Guan et al., "Delayed enrichment for c-kit and inducing cardiac differentiation attenuated protective effects of BMSCs' transplantation in pig model of acute myocardial ischemia," Cardiovascular Therapeutics, vol. 33, no. 4, pp. 184-192, 2015.

[126] V. Y. Mykhaylichenko, A. V. Kubyshkin, S. A. Samarin, I. I. Fomochkina, and L. V. Anisimova, "Experimental induction of reparative morphogenesis and adaptive reserves in the ischemic myocardium using multipotent mesenchymal bone marrow-derived stem cells," Pathophysiology, vol. 23, no. 2, pp. 95-104, 2016.

[127] T. M. A. Mohamed, N. R. Stone, E. C. Berry et al., "Chemical enhancement of in vitro and in vivo direct cardiac reprogramming," Circulation, vol. 135, no. 10, pp. 978-995, 2017.

[128] Y. Kalantar Motamedi, M. Peymani, H. Baharvand et al.et al., "Systematic selection of small molecules to promote differentiation of embryonic stem cells and experimental validation for generating cardiomyocytes," Cell Death Discovery, vol. 2, article 16007, 2016.

[129] J. S. Aguilar, A. N. Begum, J. Alvarez, X.-B. Zhang, Y. Hong, and J. Hao, "Directed cardiomyogenesis of human pluripotent stem cells by modulating Wnt/ $\beta$-catenin and BMP signalling with small molecules," Biochemical Journal, vol. 469, no. 2, pp. 235-241, 2015.

[130] X. Ma, L. Kong, and S. Zhu, "Reprogramming cell fates by small molecules," Protein \& Cell, vol. 8, no. 5, pp. 328-348, 2017.

[131] H. Wang, N. Cao, C. I. Spencer et al., "Small molecules enable cardiac reprogramming of mouse fibroblasts with a single factor, oct4," Cell Reports, vol. 6, no. 5, pp. 951-960, 2014.

[132] J. Lewandowski, T. J. Kolanowski, and M. Kurpisz, “Techniques for the induction of human pluripotent stem cell differentiation towards cardiomyocytes," Journal of Tissue Engineering and Regenerative Medicine, vol. 11, no. 5, pp. 1658-1674, 2017.

[133] J. Bartunek, A. Behfar, D. Dolatabadi et al., "Cardiopoietic stem cell therapy in heart failure: the C-CURE (cardiopoietic stem cell therapy in heart failURE) multicenter randomized trial with lineage-specified biologics," Journal of the American College of Cardiology, vol. 61, no. 23, pp. 2329-2338, 2013.

[134] F. Zemani, J. S. Silvestre, F. Fauvel-Lafeve et al., "Ex vivo priming of endothelial progenitor cells with SDF-1 before transplantation could increase their proangiogenic potential," Arteriosclerosis, Thrombosis, and Vascular Biology, vol. 28, no. 4, pp. 644-650, 2008.

[135] Z. Pasha, Y. Wang, R. Sheikh, D. Zhang, T. Zhao, and M. Ashraf, "Preconditioning enhances cell survival and differentiation of stem cells during transplantation in infarcted myocardium," Cardiovascular Research, vol. 77, no. 1, pp. 134-142, 2008.

[136] J. L. Herrmann, Y. Wang, A. M. Abarbanell, B. R. Weil, J. Tan, and D. R. Meldrum, "Preconditioning mesenchymal stem cells with transforming growth factor-alpha improves mesenchymal stem cell-mediated cardioprotection," Shock, vol. 33, no. 1, pp. 24-30, 2010.

[137] T. I. Cornu, C. Mussolino, and T. Cathomen, "Refining strategies to translate genome editing to the clinic," Nature Medicine, vol. 23, no. 4, pp. 415-423, 2017.

[138] C. Tam, J. H. Wong, R. C. F. Cheung, T. Zuo, and T. B. Ng, "Therapeutic potentials of short interfering RNAs," Applied Microbiology and Biotechnology, vol. 101, no. 19, pp. 70917111, 2017.

[139] F.-W. Tseng, M.-J. Tsai, L.-Y. Yu, Y.-S. Fu, W.-C. Huang, and H. Cheng, "Comparative effects of bone marrow mesenchymal stem cells on lipopolysaccharide-induced microglial activation," Oxidative Medicine and Cellular Longevity, vol. 2013, Article ID 234179, 10 pages, 2013.

[140] L. L. Bagno, D. Carvalho, F. Mesquita et al., "Sustained IGF-1 secretion by adipose-derived stem cells improves 
infarcted heart function," Cell Transplantation, vol. 25, no. 9, pp. 1609-1622, 2016.

[141] S. Gehmert, S. Sadat, Y. H. Song, Y. Yan, and E. Alt, "The anti-apoptotic effect of IGF-1 on tissue resident stem cells is mediated via PI3-kinase dependent secreted frizzled related protein 2 (Sfrp2) release," Biochemical and Biophysical Research Communications, vol. 371, no. 4, pp. 752-755, 2008.

[142] G. Gómez-Mauricio, I. Moscoso, M.-F. Martín-Cancho et al., "Combined administration of mesenchymal stem cells overexpressing IGF-1 and HGF enhances neovascularization but moderately improves cardiac regeneration in a porcine model," Stem Cell Research \& Therapy, vol. 7, no. 1, p. 94, 2016.

[143] L. Li, Q. Guan, S. Dai, W. Wei, and Y. Zhang, "Integrin $\beta 1$ increases stem cell survival and cardiac function after myocardial infarction," Frontiers in Pharmacology, vol. 8, 2017.

[144] Q. Mao, C. Lin, J. Gao et al., "Mesenchymal stem cells overexpressing integrin-linked kinase attenuate left ventricular remodeling and improve cardiac function after myocardial infarction," Molecular and Cellular Biochemistry, vol. 397, no. 1-2, pp. 203-214, 2014.

[145] X. Xue, Y. Liu, J. Zhang, T. Liu, Z. Yang, and H. Wang, "Bcl$\mathrm{xL}$ genetic modification enhanced the therapeutic efficacy of mesenchymal stem cell transplantation in the treatment of heart infarction," Stem Cells International, vol. 2015, Article ID 176409, 14 pages, 2015.

[146] Z. Ruan, L. Zhu, Y. Yin, and G. Chen, "Overexpressing NKx2.5 increases the differentiation of human umbilical cord drived mesenchymal stem cells into cardiomyocyte-like cells," Biomed Pharmacother, vol. 78, pp. 110-115, 2016.

[147] Y. Wang, S.-Q. Wang, L.-P. Wang et al., "Overexpression of cardiac-specific kinase TNNI3K promotes mouse embryonic stem cells differentiation into cardiomyocytes," Cellular Physiology and Biochemistry, vol. 41, no. 1, pp. 381-398, 2017.

[148] S. Golpanian, A. Wolf, K. E. Hatzistergos, and J. M. Hare, "Rebuilding the damaged heart: mesenchymal stem cells, cell-based therapy, and engineered heart tissue," Physiological Reviews, vol. 96, no. 3, pp. 1127-1168, 2016.

[149] H. K. Haider, A. Mustafa, Y. Feng, and M. Ashraf, "Genetic modification of stem cells for improved therapy of the infarcted myocardium," Molecular Pharmaceutics, vol. 8, no. 5, pp. 1446-1457, 2011.

[150] P. Prathipati, S. S. Nandi, and P. K. Mishra, "Stem cellderived exosomes, autophagy, extracellular matrix turnover, and miRNAs in cardiac regeneration during stem cell therapy," Stem Cell Reviews and Reports, vol. 13, no. 1, pp. 79-91, 2017.

[151] H. Lemcke, G. Steinhoff, and R. David, "Gap junctional shuttling of miRNA - a novel pathway of intercellular gene regulation and its prospects in clinical application," Cellular Signalling, vol. 27, no. 12, pp. 2506-2514, 2015.

[152] R. C. Lee, R. L. Feinbaum, and V. Ambros, "The C. elegans heterochronic gene lin-4 encodes small RNAs with antisense complementarity to lin-14," Cell, vol. 75, no. 5, pp. 843-854, 1993.

[153] B. Wightman, I. Ha, and G. Ruvkun, "Posttranscriptional regulation of the heterochronic gene lin-14 by lin-4 mediates temporal pattern formation in C. elegans," Cell, vol. 75, no. 5, pp. 855-862, 1993.

[154] S. Y. Lee, O. Ham, M. J. Cha et al., "The promotion of cardiogenic differentiation of hMSCs by targeting epidermal growth factor receptor using microRNA-133a," Biomaterials, vol. 34, no. 1, pp. 92-99, 2013.

[155] D. Dakhlallah, J. Zhang, L. Yu, C. B. Marsh, M. G. Angelos, and M. Khan, "MicroRNA-133a engineered mesenchymal stem cells augment cardiac function and cell survival in the infarct heart," Journal of Cardiovascular Pharmacology, vol. 65, no. 3, pp. 241-251, 2015.

[156] C. Y. Lee, S. Shin, J. Lee et al., "Microrna-mediated downregulation of apoptosis signal-regulating kinase 1 (ASK1) attenuates the apoptosis of human mesenchymal stem cells (MSCs) transplanted into infarcted heart," International Journal of Molecular Sciences, vol. 17, no. 10, 2016.

[157] H.-H. Seo, S.-Y. Lee, C. Y. Lee et al., "Exogenous miRNA146a enhances the therapeutic efficacy of human mesenchymal stem cells by increasing vascular endothelial growth factor secretion in the ischemia/reperfusion-injured heart," Journal of Vascular Research, vol. 54, no. 2, pp. 100-108, 2017.

[158] F. Huang, X. Zhu, H. XQ et al., "Mesenchymal stem cells modified with miR-126 release angiogenic factors and activate Notch ligand Delta-like-4, enhancing ischemic angiogenesis and cell survival," International Journal of Molecular Medicine, vol. 31, no. 2, pp. 484-492, 2013.

[159] D. Joladarashi, V. N. Srikanth Garikipati, R. A. Thandavarayan et al., "Enhanced cardiac regenerative ability of stem cells after ischemia-reperfusion injury: role of human CD34+ cells deficient in microRNA-377," Journal of the American College of Cardiology, vol. 66, no. 20, pp. 2214-2226, 2015.

[160] J. Liang, W. Huang, W. Cai et al., "Inhibition of microRNA495 enhances therapeutic angiogenesis of human induced pluripotent stem cells," Stem Cells, vol. 35, no. 2, pp. 337350, 2017.

[161] X.-L. Zhao, B. Yang, L.-N. Ma, and Y.-H. Dong, "MicroRNA1 effectively induces differentiation of myocardial cells from mouse bone marrow mesenchymal stem cells," Artificial Cells, Nanomedicine, and Biotechnology, vol. 44, no. 7, pp. 1665-1670, 2015.

[162] X. Shen, B. Pan, H. Zhou et al., "Differentiation of mesenchymal stem cells into cardiomyocytes is regulated by miRNA-12 via WNT signaling pathway," Journal of Biomedical Science, vol. 24, no. 1, p. 29, 2017.

[163] A. Izarra, I. Moscoso, S. Cañón et al., "miRNA-1 and miRNA133a are involved in early commitment of pluripotent stem cells and demonstrate antagonistic roles in the regulation of cardiac differentiation," Journal of Tissue Engineering and Regenerative Medicine, vol. 11, no. 3, pp. 787-799, 2017.

[164] K. T. Kuppusamy, D. C. Jones, H. Sperber et al., "Let-7 family of microRNA is required for maturation and adultlike metabolism in stem cell-derived cardiomyocytes," Proceedings of the National Academy of Sciences, vol. 112, no. 21, article 201424042, pp. E2785-E2794, 2015.

[165] G. Steinhoff, J. Nesteruk, M. Wolfien et al., "Cardiac function improvement and bone marrow response-outcome analysis of the randomized PERFECT phase III clinical trial of intramyocardial CD133+ application after myocardial infarction," EBioMedicine, vol. 22, pp. 208-224, 2017.

[166] A. Jamaiyar, W. Wan, V. Ohanyan et al., "Alignment of inducible vascular progenitor cells on a micro-bundle scaffold improves cardiac repair following myocardial infarction," Basic Research in Cardiology, vol. 112, no. 4, p. 41, 2017.

[167] M. Tendera, W. Wojakowski, W. Rużyłło et al., "Intracoronary infusion of bone marrow-derived selected CD34+CXCR4 
+ cells and non-selected mononuclear cells in patients with acute STEMI and reduced left ventricular ejection fraction: results of randomized, multicentre Myocardial Regeneration by Intracoronary Infusion of Selected Population of Stem Cells in Acute Myocardial Infarction (REGENT) trial," European Heart Journal, vol. 30, no. 11, pp. 13131321, 2009.

[168] C. G. Palii, B. Vulesevic, S. Fraineau et al., "Trichostatin a enhances vascular repair by injected human endothelial progenitors through increasing the expression of TAL1dependent genes," Cell Stem Cell, vol. 14, no. 5, pp. 644657, 2014.

[169] D. W. Losordo, T. D. Henry, C. Davidson et al., "Intramyocardial, autologous CD34+ cell therapy for refractory angina," Circulation Research, vol. 109, no. 4, pp. 428-436, 2011.

[170] B. Assmus, D. H. Walter, F. H. Seeger et al., "Effect of shock wave-facilitated intracoronary cell therapy on LVEF in patients with chronic heart failure: the CELLWAVE randomized clinical trial," JAMA, vol. 309, no. 15, pp. 1622-1631, 2013.

[171] J. R. Teerlink, M. Metra, G. S. Filippatos et al., "Benefit of cardiopoietic mesenchymal stem cell therapy on left ventricular remodelling: results from the Congestive Heart Failure Cardiopoietic Regenerative Therapy (CHART-1) study," European Journal of Heart Failure, vol. 19, no. 11, pp. 1520-1529, 2017.

[172] R. Sanz-Ruiz, A. Casado Plasencia, L. R. Borlado et al., "Rationale and design of a clinical trial to evaluate the safety and efficacy of intracoronary infusion of allogeneic human cardiac stem cells in patients with acute myocardial infarction and left ventricular dysfunction novelty and significance," Circulation Research, vol. 121, no. 1, pp. 71-80, 2017.

[173] S. Ishigami, S. Ohtsuki, T. Eitoku et al., "Intracoronary cardiac progenitor cells in single ventricle physiology: the perseus (cardiac progenitor cell infusion to treat univentricular heart disease) randomized phase 2 trial," Circulation Research, vol. 120, no. 7, pp. 1162-1173, 2017.

[174] K. Malliaras, R. R. Makkar, R. R. Smith et al., "Intracoronary cardiosphere-derived cells after myocardial infarction," Journal of the American College of Cardiology, vol. 63, no. 2, pp. 110-122, 2014.

[175] V. Bellamy, V. Vanneaux, A. Bel et al., "Long-term functional benefits of human embryonic stem cell-derived cardiac progenitors embedded into a fibrin scaffold," The Journal of Heart and Lung Transplantation, vol. 34, no. 9, pp. 11981207, 2015.

[176] F. E. Ezquer, M. E. Ezquer, J. M. Vicencio, and S. D. Calligaris, "Two complementary strategies to improve cell engraftment in mesenchymal stem cell-based therapy: increasing transplanted cell resistance and increasing tissue receptivity," Cell Adhesion and Migration, vol. 11, no. 1, pp. 110-119, 2016.

[177] S. Chen, L. Chen, X. Wu et al., "Ischemia postconditioning and mesenchymal stem cells engraftment synergistically attenuate ischemia reperfusion-induced lung injury in rats," Journal of Surgical Research, vol. 178, no. 1, pp. 81-91, 2012.

[178] Q. Jiang, P. Song, E. Wang, J. Li, S. Hu, and H. Zhang, "Remote ischemic postconditioning enhances cell retention in the myocardium after intravenous administration of bone marrow mesenchymal stromal cells," Journal of Molecular and Cellular Cardiology, vol. 56, pp. 1-7, 2013.
[179] Q. Jiang, T. Yu, K. Huang, J. Lu, H. Zhang, and S. Hu, "Remote ischemic postconditioning ameliorates the mesenchymal stem cells engraftment in reperfused myocardium," PLoS One, vol. 11, no. 1, article e0146074, 2016.

[180] Z. Zhang, S. Li, M. Cui et al., "Rosuvastatin enhances the therapeutic efficacy of adipose-derived mesenchymal stem cells for myocardial infarction via PI3K/Akt and MEK/ERK pathways," Basic Research in Cardiology, vol. 108, no. 2, p. 333, 2013.

[181] Y. J. Yang, H. Y. Qian, J. Huang et al., “Atorvastatin treatment improves survival and effects of implanted mesenchymal stem cells in post-infarct swine hearts," European Heart Journal, vol. 29, no. 12, pp. 1578-1590, 2008.

[182] A. Aicher, C. Heeschen, K.-i. Sasaki, C. Urbich, A. M. Zeiher, and S. Dimmeler, "Low-energy shock wave for enhancing recruitment of endothelial progenitor cells: a new modality to increase efficacy of cell therapy in chronic hind limb ischemia," Circulation, vol. 114, no. 25, pp. 2823-2830, 2006.

[183] S. H. Chou, S. Z. Lin, W. W. Kuo et al., "Mesenchymal stem cell insights: prospects in cardiovascular therapy," Cell Transplantation, vol. 23, no. 4-5, pp. 513-529, 2014.

[184] W. Gu, X. Hong, C. Potter, A. Qu, and Q. Xu, "Mesenchymal stem cells and vascular regeneration," Microcirculation, vol. 24, no. 1, article e12324, 2017.

[185] M. S. de Oliveira, F. Saldanha-Araujo, A. M. de Goes, F. F. Costa, and J. L. de Carvalho, "Stem cells in cardiovascular diseases: turning bad days into good ones," Drug Discovery Today, vol. 22, no. 11, pp. 1730-1739, 2017.

[186] R. D. Kirkton and N. Bursac, "Genetic engineering and stem cells: combinatorial approaches for cardiac cell therapy [Cellular/Tissue Engineering]," IEEE Engineering in Medicine and Biology Magazine, vol. 27, no. 3, pp. 8588, 2008.

[187] I. Huber, I. Itzhaki, O. Caspi et al., "Identification and selection of cardiomyocytes during human embryonic stem cell differentiation," The FASEB Journal, vol. 21, no. 10, pp. 2551-2563, 2007.

[188] M. Krishnan, J. M. Park, F. Cao et al., "Effects of epigenetic modulation on reporter gene expression: implications for stem cell imaging," The FASEB Journal, vol. 20, pp. 106108, 2005.

[189] R. W. Grauss, J. van Tuyn, P. Steendijk et al., "Forced myocardin expression enhances the therapeutic effect of human mesenchymal stem cells after transplantation in ischemic mouse hearts," Stem Cells, vol. 26, no. 4, pp. 10831093, 2008.

[190] H. He, Z.-H. Zhao, F.-S. Han, X.-H. Liu, R. Wang, and Y.-J. Zeng, "Overexpression of protein kinase $\mathrm{C} \varepsilon$ improves retention and survival of transplanted mesenchymal stem cells in rat acute myocardial infarction," Cell Death and Disease, vol. 7, no. 1, article e2056, 2016.

[191] L. Li, X. Chen, W. E. Wang, and C. Zeng, "How to improve the survival of transplanted mesenchymal stem cell in ischemic heart?," Stem Cells International, vol. 2016, pp. 1-14, 2016.

[192] A. Pan, N. L. Weintraub, and Y. Tang, "Enhancing stem cell survival in an ischemic heart by CRISPR-dCas9-based gene regulation," Medical Hypotheses, vol. 83, no. 6, pp. 702-705, 2014.

[193] Y. Dai, M. Xu, Y. Wang, Z. Pasha, T. Li, and M. Ashraf, "HIF- $1 \alpha$ induced-VEGF overexpression in bone marrow 
stem cells protects cardiomyocytes against ischemia," Journal of Molecular and Cellular Cardiology, vol. 42, no. 6, pp. 10361044, 2007.

[194] A. Schajnovitz, T. Itkin, G. D’Uva et al., "CXCL12 secretion by bone marrow stromal cells is dependent on cell contact and mediated by connexin-43 and connexin-45 gap junctions," Nature Immunology, vol. 12, no. 5, pp. 391-398, 2011.

[195] L. Zhao, X. Liu, Y. Zhang et al., "Enhanced cell survival and paracrine effects of mesenchymal stem cells overexpressing hepatocyte growth factor promote cardioprotection in myocardial infarction," Experimental Cell Research, vol. 344, no. 1, pp. 30-39, 2016.

[196] W. SZ, Y. L. Li, W. Huang et al., "Paracrine effect of CXCR4overexpressing mesenchymal stem cells on ischemic heart injury," Cell Biochemistry and Function, vol. 35, pp. 113123, 2017.

[197] A. Barhanpurkar-Naik, S. T. Mhaske, S. T. Pote, K. Singh, and M. R. Wani, "Interleukin-3 enhances the migration of human mesenchymal stem cells by regulating expression of CXCR4," Stem Cell Research \& Therapy, vol. 8, no. 1, p. 168, 2017.

[198] F. Nitzsche, C. Müller, B. Lukomska, J. Jolkkonen, A. Deten, and J. Boltze, "Concise review: MSC adhesion cascade-insights into homing and transendothelial migration," Stem Cells, vol. 35, no. 6, pp. 1446-1460, 2017.

[199] L. Hou, J. J. Kim, Y. J. Woo et al., "Stem cell-based therapies to promote angiogenesis in ischemic cardiovascular disease," American Journal of Physiology - Heart and Circulatory Physiology, vol. 310, no. 4, pp. H455-H465, 2016.

[200] F. Bortolotti, G. Ruozi, A. Falcione et al., "In vivo functional selection identifies cardiotrophin-1 as a cardiac engraftment factor for mesenchymal stromal cells," Circulation, vol. 136, no. 16, pp. 1509-1524, 2017.

[201] F. H. Seeger, A. M. Zeiher, and S. Dimmeler, "MicroRNAs in stem cell function and regenerative therapy of the heart," Arteriosclerosis, Thrombosis, and Vascular Biology, vol. 33, no. 8, pp. 1739-1746, 2013.

[202] Y. B. Chen, L. Y. W. Bin, T. H. Hung et al., "Mesenchymal stem cell-based HSP70 promoter-driven VEGFA induction by resveratrol promotes angiogenesis in a mouse model," Cell Stress Chaperones, vol. 20, no. 4, pp. 643-652, 2015.

[203] T. A. Markel, Y. Wang, J. L. Herrmann et al., "VEGF is critical for stem cell-mediated cardioprotection and a crucial paracrine factor for defining the age threshold in adult and neonatal stem cell function," AJP: Heart and Circulatory Physiology, vol. 295, no. 6, pp. H2308-H2314, 2008.

[204] H. H. Moon, M. K. Joo, H. Mok et al., "MSC-based VEGF gene therapy in rat myocardial infarction model using facial amphipathic bile acid-conjugated polyethyleneimine," Biomaterials, vol. 35, no. 5, pp. 1744-1754, 2014.

[205] J. Chen, R. Crawford, C. Chen, and Y. Xiao, "The key regulatory roles of the PI3K/Akt signalling pathway in the functionalities of mesenchymal stem cells and applications in tissue regeneration," Tissue Engineering Part B: Reviews, vol. 19, no. 6, pp. 516-528, 2013.

[206] Z. Wen, W. Huang, Y. Feng et al., "MicroRNA-377 regulates mesenchymal stem cell-induced angiogenesis in ischemic hearts by targeting VEGF," PLoS One, vol. 9, no. 9, article e104666, 2014.

[207] J. J. Chen and S. H. Zhou, "Mesenchymal stem cells overexpressing MiR-126 enhance ischemic angiogenesis via the
AKT/ERK-related pathway," Cardiology Journal, vol. 18, no. 6, pp. 675-681, 2011

[208] Y. L. Zeng, H. Zheng, Q. R. Chen et al., "Bone marrowderived mesenchymal stem cells overexpressing miR-21 efficiently repair myocardial damage in rats," Oncotarget, vol. 8, no. 17, pp. 29161-29173, 2017.

[209] S. C. Suresh, V. Selvaraju, M. Thirunavukkarasu et al., "Thioredoxin-1 (Trx1) engineered mesenchymal stem cell therapy increased pro-angiogenic factors, reduced fibrosis and improved heart function in the infarcted rat myocardium," International Journal of Cardiology, vol. 201, pp. 517$528,2015$.

[210] J. Wang, X. Hu, and H. Jiang, "MSCs modified with HO-1 gene transplantation: a novel therapeutic approach for attenuating heart failure," International Journal of Cardiology, vol. 214, pp. 159-160, 2016.

[211] H. Niess, J. C. von Einem, M. N. Thomas et al., "Treatment of advanced gastrointestinal tumors with genetically modified autologous mesenchymal stromal cells (TREAT-ME1): study protocol of a phase I/II clinical trial," BMC Cancer, vol. 15, pp. 1-13, 2015.

[212] E. K. Sage, R. M. Thakrar, and S. M. Janes, "Genetically modified mesenchymal stromal cells in cancer therapy," Cytotherapy, vol. 18, no. 11, pp. 1435-1445, 2016.

[213] X. J-Y, G.-H. Chen, and Y.-J. Yang, "Exosomes: a rising star in failing hearts," Frontiers in Physiology, vol. 8, 2017.

[214] N. P. Hessvik and A. Llorente, "Current knowledge on exosome biogenesis and release," Cellular and Molecular Life Sciences, 2017.

[215] X. Teng, L. Chen, W. Chen, J. Yang, Z. Yang, and Z. Shen, "Mesenchymal stem cell-derived exosomes improve the microenvironment of infarcted myocardium contributing to angiogenesis and anti-inflammation," Cellular Physiology and Biochemistry, vol. 37, no. 6, pp. 2415-2424, 2015.

[216] Z. Zhang, J. Yang, W. Yan, Y. Li, Z. Shen, and T. Asahara, "Pretreatment of cardiac stem cells with exosomes derived from mesenchymal stem cells enhances myocardial repair," Journal of the American Heart Association, vol. 5, no. 1, article e002856, 2016.

[217] X. Cui, Z. He, Z. Liang, Z. Chen, H. Wang, and J. Zhang, "Exosomes from adipose-derived mesenchymal stem cells protect the myocardium against ischemia/reperfusion injury through Wnt/ $\beta$-Catenin signaling pathway," Journal of Cardiovascular Pharmacology, vol. 70, no. 4, pp. 225231, 2017.

[218] S. Bian, L. Zhang, L. Duan, X. Wang, Y. Min, and H. Yu, "Extracellular vesicles derived from human bone marrow mesenchymal stem cells promote angiogenesis in a rat myocardial infarction model," Journal of Molecular Medicine, vol. 92, no. 4, pp. 387-397, 2014.

[219] V. Börger, M. Bremer, R. Ferrer-Tur et al., "Mesenchymal stem/stromal cell-derived extracellular vesicles and their potential as novel immunomodulatory therapeutic agents," International Journal of Molecular Sciences, vol. 18, no. 7, p. 1450, 2017.

[220] L. Shao, Y. Zhang, B. Lan et al., "MiRNA-sequence indicates that mesenchymal stem cells and exosomes have similar mechanism to enhance cardiac repair," BioMed Research International, vol. 2017, Article ID 4150705, 9 pages, 2017.

[221] H. Zhang, M. Xiang, D. Meng, N. Sun, and S. Chen, "Inhibition of myocardial ischemia/reperfusion injury by exosomes 
secreted from mesenchymal stem cells," Stem Cells International, vol. 2016, Article ID 4328362, 8 pages, 2016.

[222] M. Gnecchi, H. He, O. D. Liang et al., "Paracrine action accounts for marked protection of ischemic heart by Aktmodified mesenchymal stem cells," Nature Medicine, vol. 11, no. 4, pp. 367-368, 2005.

[223] J. Ma, Y. Zhao, L. Sun et al., "Exosomes derived from Aktmodified human umbilical cord mesenchymal stem cells improve cardiac regeneration and promote angiogenesis via activating platelet-derived growth factor D," STEM CELLS Translational Medicine, vol. 6, no. 1, pp. 51-59, 2017.

[224] H. Gonzalez-King, N. A. García, I. Ontoria-Oviedo, M. Ciria, J. A. Montero, and P. Sepúlveda, "Hypoxia inducible factor$1 \alpha$ potentiates Jagged 1-mediated angiogenesis by mesenchymal stem cell-derived exosomes," Stem Cells, vol. 35, no. 7, pp. 1747-1759, 2017.

[225] K. Kang, R. Ma, W. Cai et al., "Exosomes secreted from CXCR4 Overexpressing mesenchymal stem cells promote cardioprotection via Akt signaling pathway following myocardial infarction," Stem Cells International, vol. 2015, pp. 1-14, 2015.

[226] B. Yu, W. H. Kim, M. Gong et al., "Exosomes secreted from GATA-4 overexpressing mesenchymal stem cells serve as a reservoir of anti-apoptotic microRNAs for cardioprotection," International Journal of Cardiology, vol. 182, pp. 349-360, 2015.

[227] E. Suzuki, D. Fujita, M. Takahashi, S. Oba, and H. Nishimatsu, "Adipose tissue-derived stem cells as a therapeutic tool for cardiovascular disease," World Journal of Cardiology, vol. 7, no. 8, pp. 454-465, 2015.

[228] P. P. Zwetsloot, H. Gremmels, B. Assmus et al., "Responder definition in clinical stem cell trials in cardiology: will the real responder please stand up?," Circulation Research, vol. 119, no. 4, pp. 514-518, 2016.

[229] R. Delewi, A. Hirsch, J. G. Tijssen et al., "Impact of intracoronary bone marrow cell therapy on left ventricular function in the setting of ST-segment elevation myocardial infarction: a collaborative meta-analysis," European Heart Journal, vol. 35, no. 15, pp. 989-998, 2014.

[230] J. V. Jokerst, N. Cauwenberghs, T. Kuznetsova et al., "Circulating biomarkers to identify responders in cardiac cell therapy," Scientific Reports, vol. 7, no. 1, pp. 44194419, 2017.

[231] J. Kim, L. Shapiro, and A. Flynn, "The clinical application of mesenchymal stem cells and cardiac stem cells as a therapy for cardiovascular disease," Pharmacology and Therapeutics, vol. 151, pp. 8-15, 2015.

[232] A. Singh, A. Singh, and D. Sen, "Mesenchymal stem cells in cardiac regeneration: a detailed progress report of the last 6 years (2010-2015)," Stem Cell Research \& Therapy, vol. 7, no. 1, p. 82, 2016.

[233] J. M. Hare, D. L. DiFede, A. C. Rieger et al., "Randomized comparison of allogeneic versus autologous mesenchymal stem cells for nonischemic dilated cardiomyopathy: POSEIDON-DCM trial," Journal of the American College of Cardiology, vol. 69, no. 5, pp. 526-537, 2017.

[234] J. G. Bartolucci, F. J. Verdugo, P. L. González et al., "Safety and efficacy of the intravenous infusion of umbilical cord mesenchymal stem cells in patients with heart failure: a phase $1 / 2$ randomized controlled trial (RIMECARD trial)," Circulation Research, vol. 121, no. 10, pp. 1192-1204, 2017.
[235] A. B. Mathiasen, A. A. Qayyum, E. Jørgensen et al., "Bone marrow-derived mesenchymal stromal cell treatment in patients with severe ischaemic heart failure: a randomized placebo-controlled trial (MSC-HF trial)," European Heart Journal, vol. 36, no. 27, pp. 1744-1753, 2015.

[236] W. Xiao, S. Guo, C. Gao et al., "A randomized comparative study on the efficacy of intracoronary infusion of autologous bone marrow mononuclear cells and mesenchymal stem cells in patients with dilated cardiomyopathy," International Heart Journal, vol. 58, no. 2, pp. 238-244, 2017.

[237] E. C. Perin, K. M. Borow, G. V. Silva et al., "A phase II doseescalation study of allogeneic mesenchymal precursor cells in patients with ischemic or nonischemic heart failure," Circulation Research, vol. 117, no. 6, pp. 576-584, 2015.

[238] A. Can, A. T. Ulus, O. Cinar et al., "Human Umbilical Cord Mesenchymal Stromal Cell Transplantation in Myocardial Ischemia (HUC-HEART Trial). A study protocol of a phase $1 / 2$, controlled and randomized trial in combination with coronary artery bypass grafting," Stem Cell Reviews and Reports, vol. 11, no. 5, pp. 752-760, 2015.

[239] J. Butler, S. E. Epstein, S. J. Greene et al., "Intravenous allogeneic mesenchymal stem cells for nonischemic cardiomyopathy: safety and efficacy results of a phase II-A randomized trial," Circulation Research, vol. 120, no. 2, pp. 332-340, 2017.

[240] A. W. Heldman, D. L. DiFede, J. E. Fishman et al., “Transendocardial mesenchymal stem cells and mononuclear bone marrow cells for ischemic cardiomyopathy," JAMA, vol. 311, no. 1, pp. 62-73, 2014.

[241] D. Guijarro, M. Lebrin, O. Lairez et al., "Intramyocardial transplantation of mesenchymal stromal cells for chronic myocardial ischemia and impaired left ventricular function: results of the MESAMI 1 pilot trial," International Journal of Cardiology, vol. 209, pp. 258-265, 2016.

[242] K. Anastasiadis, P. Antonitsis, S. Westaby et al., "Implantation of a novel allogeneic mesenchymal precursor cell type in patients with ischemic cardiomyopathy undergoing coronary artery bypass grafting: an open label phase IIa trial," Journal of Cardiovascular Translational Research, vol. 9, no. 3, pp. 202-213, 2016.

[243] S. Chen, W. Fang, F. Ye et al., "Effect on left ventricular function of intracoronary transplantation of autologous bone marrow mesenchymal stem cell in patients with acute myocardial infarction," The American Journal of Cardiology, vol. 94, no. 1, pp. 92-95, 2004.

[244] J.-W. Lee, S.-H. Lee, Y.-J. Youn et al., "A randomized, open-label, multicenter trial for the safety and efficacy of adult mesenchymal stem cells after acute myocardial infarction," Journal of Korean Medical Science, vol. 29, no. 1, pp. 23-31, 2014.

[245] L. R. Gao, X. T. Pei, Q. A. Ding et al., "A critical challenge: dosage-related efficacy and acute complication intracoronary injection of autologous bone marrow mesenchymal stem cells in acute myocardial infarction," International Journal of Cardiology, vol. 168, no. 4, pp. 3191-3199, 2013.

[246] A. Chullikana, A. S. Majumdar, S. Gottipamula et al., "Randomized, double-blind, phase I/II study of intravenous allogeneic mesenchymal stromal cells in acute myocardial infarction," Cytotherapy, vol. 17, no. 3, pp. 250-261, 2015.

[247] X. Wang, W. Xi, and F. Wang, "The beneficial effects of intracoronary autologous bone marrow stem cell transfer as an adjunct to percutaneous coronary intervention in patients 
with acute myocardial infarction," Biotechnology Letters, vol. 36, no. 11, pp. 2163-2168, 2014.

[248] S. F. Rodrigo, J. van Ramshorst, G. E. Hoogslag et al., "Intramyocardial injection of autologous bone marrow-derived ex vivo expanded mesenchymal stem cells in acute myocardial infarction patients is feasible and safe up to 5 years of follow-up," Journal of Cardiovascular Translational Research, vol. 6, no. 5, pp. 816-825, 2013.

[249] L. R. Gao, Y. Chen, N. K. Zhang et al., "Intracoronary infusion of Wharton's jelly-derived mesenchymal stem cells in acute myocardial infarction: double-blind, randomized controlled trial," BMC Medicine, vol. 13, no. 1, p. 162, 2015. 


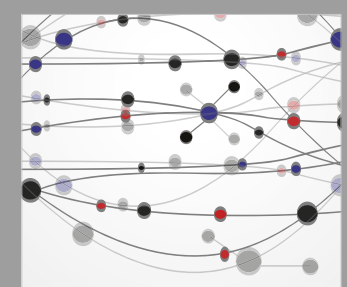

The Scientific World Journal
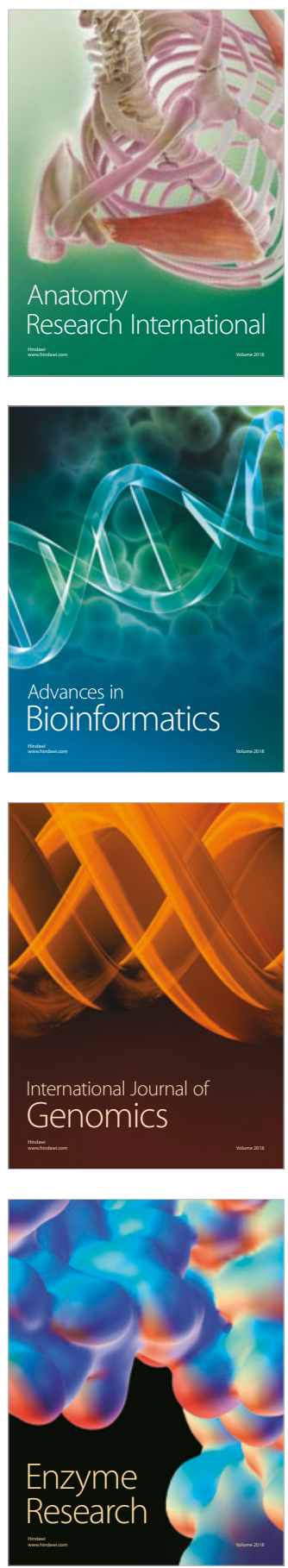
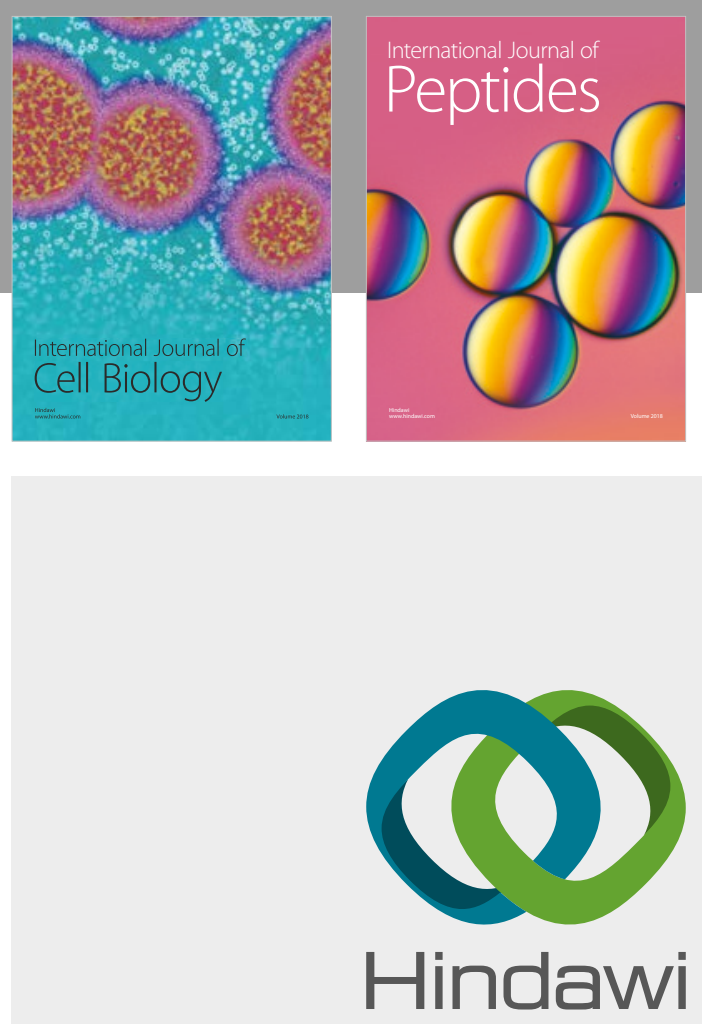

Submit your manuscripts at

www.hindawi.com
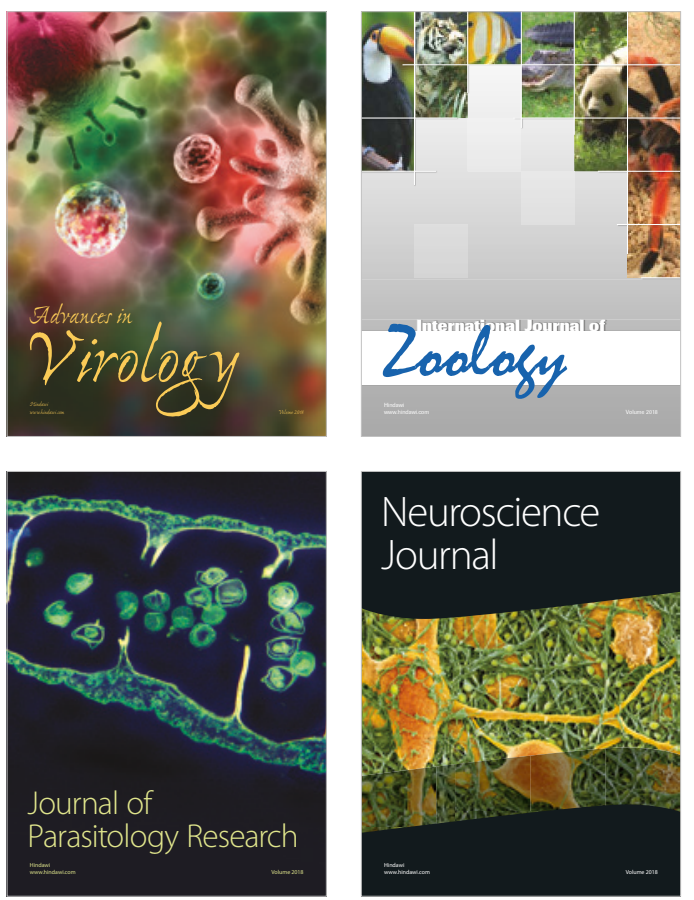
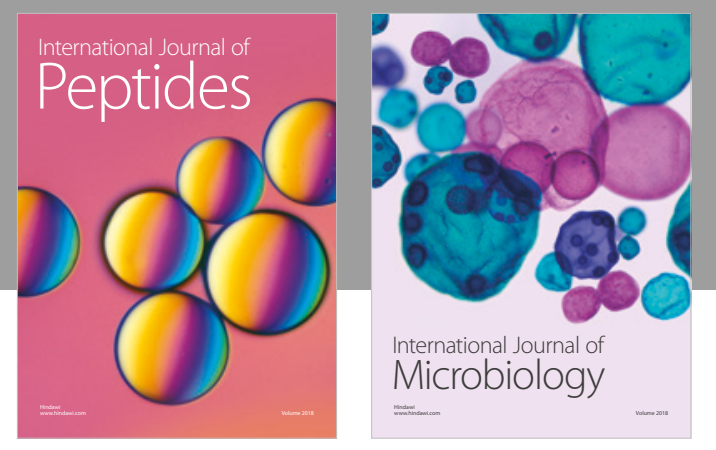

nternational Journal of Microbiology
Journal of
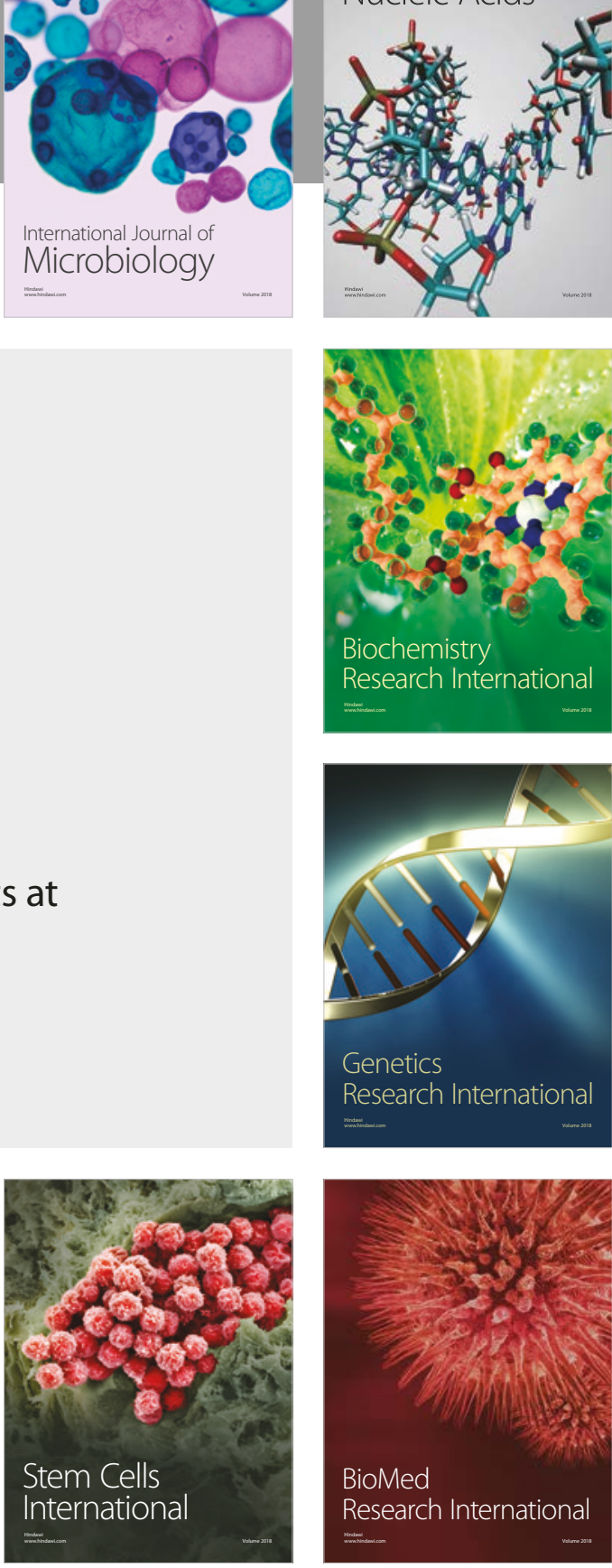
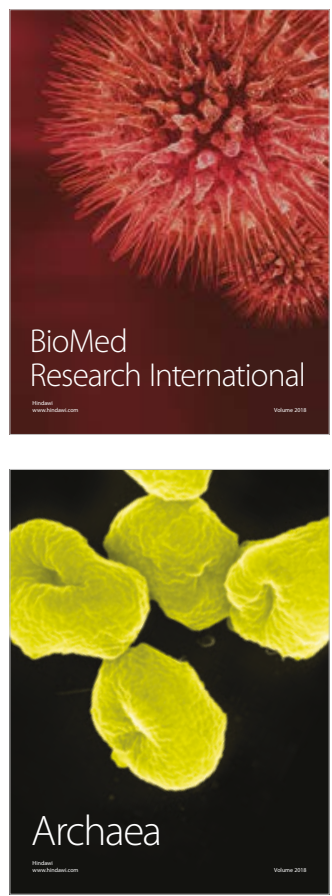